\title{
Blending Octane Number of Ethanol in HCCI, SI and CI Combustion Modes
}

\author{
Muhammad Waqas, Nimal Naser, and Mani Sarathy \\ King Abdullah Univ of Science \& Tech \\ Kai Morganti \\ Saudi Aramco \\ Khalid Al-Qurashi and Bengt Johansson \\ King Abdullah Univ of Science \& Tech
}

\begin{abstract}
The effect of ethanol blended with three FACE (Fuels for Advanced Combustion Engines) gasolines, I, J and A corresponding to RON 70.3, 71.8 and 83.5, respectively, were compared to PRF70 and PRF84 with the same ethanol concentrations, these being $2 \%, 5 \%$, $10 \%, 15 \%$ and $20 \%$ by volume. A Cooperative Fuel Research (CFR) engine was used to understand the blending effect of ethanol with FACE gasolines and PRFs in spark-ignited and homogeneous charge compression ignited mode. Blending octane numbers (BON) were obtained for both the modes. All the fuels were also tested in an ignition quality tester to obtain Blending Derived Cetane numbers $(\mathrm{BDCN})$. It is shown that fuel composition and octane number are important characteristics of all the base fuels that have a significant impact on octane increase with ethanol. The dependency of octane number for the base fuel on the blending octane number depended on the combustion mode operated. The aromatic composition in the base fuel, effects blending octane number of the mixture, for fuels with higher aromatic content lower blending octane numbers were observed for ethanol concentration.
\end{abstract}

CITATION: Waqas, M., Naser, N., Sarathy, M., Morganti, K. et al., "Blending Octane Number of Ethanol in HCCI, SI and CI Combustion Modes," SAE Int. J. Fuels Lubr. 9(3):2016, doi:10.4271/2016-01-2298.

\section{INTRODUCTION}

Ethanol has a research octane number (RON) 108 [1]. This is higher than gasoline, which is typically RON 92 to 97 [2]]. Ethanol has been widely accepted as a transportation fuel either in its pure form or in a blend with gasoline. Ethanol acts as an octane enhancer and its addition to gasoline helps to increase the mixture's octane number and thereby reduce tendency to knock [ $\underline{3}$ ]. It has been indicated that the use of ethanol in conjunction with a gasoline helps to increase the engine efficiency, torque and power compared to the baseline gasoline [].

Global increasing energy demand and the forthcoming stringent emission regulations require high efficiency and low emissions for future combustion engines. Raising the octane rating of the fuel can enable to higher compression ratios and boost levels giving lower fuel consumption [ $[$ ]. The utilization of a biofuel such as ethanol together with gasoline can help to solve energy security problems.

Today many gas stations in the US have started to offer ethanol as an oxygenated gasoline blend fuel, and it is not unusual to provide E85 in the form of $85 \%$ ethanol and $15 \%$ gasoline [6]. In Brazil, all cars run on either $22 \%$ or $25 \%$ ethanol-gasoline blend or pure ethanol [ $\underline{6}]$. In Sweden gasoline containing 5\% ethanol and in Australia gasoline containing $10 \%$ ethanol is used by transport vehicles [7]. Stein et al studied ethanol gasoline blends of E20-E40 and in another study E85 $[\underline{8}, \underline{9}]$. The Lower Heating Value (LHV) of ethanol is less than of gasoline $(40 \mathrm{MJ} / \mathrm{kg})$, hence volumetric fuel consumption $(1 / \mathrm{kWh})$ will be higher for the same engine efficiency [10]. On the other hand high heat of vaporization for ethanol results in high compression ratios through improved knock mitigation.

It has been found that RON increases with ethanol blending but the effect is diminished at approximately $30 \%$ ethanol by volume where the RON starts to have a constant value and eventually converges to the RON of neat ethanol [11]. A small quantity of ethanol can lead to significant rise in the RON of the blend $[\underline{1}, \underline{12}]$. Anderson et al highlighted that $10 \%$ of ethanol addition caused a significant increase in the RON of the blend [13]. It was also highlighted that the base fuel with low RON had the greatest increase in RON with $10 \%$ ethanol addition [13]. Rankovic et al reported similar observations [12]. The aromatic content in the base fuel has significant effect on the RON response, and it has been identified that the addition of aromatics will cause a decrease in the RON response with the addition of ethanol [14]. The blending of ethanol with gasoline causes a non-linear increase in the RON and non-linearity depends on the composition of the base fuel $[\underline{12}, \underline{14}]$. Foong et al investigated ethanol blended with PRF91 and with a non-oxygenated RON91 gasoline [1]. The response for PRF91 was found to be more nonlinear than the 
RON91 gasoline, highlighting that the composition of base fuel plays an important role in the non-linear RON response [1]. The nonlinearity gives rise to a blending octane number. Blending octane number have been previously used to understand the nonlinear nature of base fuel blended with ethanol [12]. The blending octane number is expressed as a function of base fuel composition, blending RON and the RON of the base fuel. For smaller quantities of octane boosters, the blending octane number is higher. The blending octane number decreases and finally approaches the same number as that of the additive at $100 \%$ concentration.

There have been many experiments performed using lower octane fuels at low engine loads and higher octane fuel for high engine loads $[\underline{7}, \underline{8}, \underline{15}, \underline{16}, \underline{17}, \underline{18}, \underline{19}, \underline{20}, \underline{21}]$. Viollet et al found that a low octane naphtha fuel (RON 61) enabled maximum brake torque (MBT) spark timing to be attained at low engine loads. At medium to high engine loads, MBT spark timing could still be maintained by adding higher RON oxygenated fuel [10]. The combination of a high and low RON fuel in separate tanks to create fuels of the required octane rating according to demand can be considered as the 'Octane-on-Demand' concept [10]. Daniel et al used ethanol to investigate the concept of double fuel injection and found that a greater degree of engine downsizing could be obtained relative to gasoline [17]. Bourhis et al investigated the viability of implementing Octane-on-Demand using a low RON naphtha fuel in conjunction with several high octane boosters [19]. Ethanol was shown to provide the greatest benefit in terms of RON boosting. Wang et al also investigated the double fuel concept by comparing the effect of fuel delivery pathway on engine performance [15]. In this case, both gasoline and ethanol were delivered to the engine using Port fuel injector (PFI) and direct injector (DI). Each combination provided fuel economy benefits, but the thermal efficiency was higher in the case where the ethanol was injected directly into the engine. This was attributed to the high latent heat of vaporization of ethanol and additional charge cooling benefits. Ojapah et al compared the performance, combustion process and emissions between four operating modes with gasoline and its blend with ethanol, E15 and E85 [22]. It was highlighted that multiple fuel injections and higher injection pressure can lead to reduction in the fuel consumption.

Another promising combustion concept that has received attention is Homogeneous Charge Compression Ignition (HCCI). The HCCI combustion is appreciated because it provides low nitric oxides $\left(\mathrm{NO}_{\mathrm{x}}\right)$ emissions and improved fuel economy $[\underline{23}, \underline{24}]$. In spark ignition (SI) engines, RON has been used to describe the anti-knock quality of the fuel [드]. Nonetheless, the RON cannot be used as an ideal parameter to describe the autoignition properties of the fuel in the HCCI combustion mode $[\underline{24}, \underline{26}, \underline{27}]$. Recently the Lund-Chevron HCCI fuel number was proposed to better describe the autoignition properties of the fuel [26]. Similar values for RON and HCCI fuel number were found for the blends of ethanol, iso-octane and nheptane at low inlet air temperatures. But at high inlet air temperatures, the RON and HCCI numbers did not match well [26]. This suggests that similar non-linear effects will occur with ethanol addition for both SI and HCCI combustion modes at low inlet temperatures. The addition of toluene in the blends of ethanol, isooctane and n-heptane also showed that the RON and HCCI numbers do not match well both for low and high inlet air temperatures [26]. The concept of dual fuel injection has also been applied in HCCI combustion mode [료, 29, $\underline{30]}$.

Compression ignition engines have been recognized as one of the most fuel efficient engines mainly due to high compression ratios and reduced throttling losses [31]. Ethanol has been considered as an alternative fuel for diesel engine in the form of ethanol-diesel blends [32]. The maximum amount of ethanol that can be added to the diesel depends on properties such as blend stability, viscosity and lubricity, energy content, material compatibility and cetane number [32].

It has been previously found that the aromatics molecules present in gasoline offers the greatest knock resistance [2]. The study will address the role of base fuel composition and octane number in the RON evolution with ethanol addition. FACE I has a RON of 70.3 and FACE J has a RON of 71.3 but the aromatic concentration for both of them differs by about 30\%. This enabled a test of how ethanol will increase octane number with a base fuel with low or high aromatic contents. As a reference PRF70 was also used with $0 \%$ aromatic.

A Cooperative Fuel Research (CFR) engine in both SI and HCCI combustion mode was used to conduct the experiments with ethanol-FACE gasoline blends and ethanol-PRF blends. Ethanol with a RON 108 was selected as the octane booster. Three low RON gasolines, FACE (Fuels for Advanced Combustion Engines) A, FACE I and FACE J were selected as base fuels. Detailed information on the FACE fuels properties can be found in the report published by Coordinating Research Council [33]. The fundamental ignition and heat release characteristics of FACE gasolines have been previously investigated $[\underline{34}, \underline{35}, \underline{36}, \underline{37}, \underline{38}]$. Ethanol with concentration by volume of $2 \%, 5 \%, 10 \%, 15 \%$ and $20 \%$ was added to the FACE fuels and two PRF solutions of RON 70 and RON 84.

For SI combustion, the CFR was operated at RON conditions that correspond to engine speed of $600 \mathrm{rpm}$, air inlet temperature of $52{ }^{\circ} \mathrm{C}$ and spark timing (ST) of -13 CAD (Crank Angle Degree). For HCCI mode the engine was operated with four conditions as shown in Table $\underline{1 .}$

The operating conditions HCCI- $1\left(600 \mathrm{rpm}, 52^{\circ} \mathrm{C}\right)$ and HCCI-4(900 $\mathrm{rpm}, 149^{\circ} \mathrm{C}$ ) were chosen to compare with RON and MON conditions in SI conditions. That involved simultaneously changing two variables (speed and temperature). The other two HCCI numbers were chosen to see the effect of changing each variable individually resulting in four HCCI numbers. Recent work by Truedsson et al also supported the selection of four HCCI numbers [26]. Five blending octane numbers $(\mathrm{BON})$ corresponding to four HCCI fuel numbers and one RON number were obtained. An Ignition Quality Tester (IQT) was also used to obtain the blending derived cetane numbers (BDCN) for all the ethanol-FACE fuels and ethanol-PRF blends. 
Table 1. Four HCCI fuel numbers

\begin{tabular}{|l|l|l|}
\hline HCCI fuel numbers & Engine speed (rpm) & $\begin{array}{l}\text { Intake air } \\
\text { Temperature } \mathrm{T}_{\text {in }}\left({ }^{\circ} \mathrm{C}\right)\end{array}$ \\
\hline HCCI-1 (RON) & 600 & 52 \\
\hline HCCI-2 & 600 & 149 \\
\hline HCCI-3 & 900 & 52 \\
\hline HCCI-4 (MON) & 900 & 149 \\
\hline
\end{tabular}

\section{EXPERIMENTAL SET UP}

A Waukesha variable compression ratio cooperative fuels research (CFR) engine was used for the experiments and operated in SI and HCCI mode. Figure 1 shows the CFR engine used for experiments. The range of compression ratio was from 4 to 15.5 with a resolution of 0.1 . The carburetor of the standard CFR engine was replaced with a port injection system. The intake air flow was measured by Elster mass flow meter. The air temperature was regulated by an air heating system which consists of three ceramic heating clamps each $400 \mathrm{~W}$. A thermocouple $3.5 \mathrm{~cm}$ upstream of fuel injector is used to measure the intake air temperature. ETAS lambda sensor was used to determine the equivalence ratio. The fuel was injected into the hot air flow with a feed fuel pressure of 6 bars. The fuel flow rate was calculated with the measured lambda and the air flow rates. An AVL GH14 D pressure transducer mounted on the cylinder was used to extract the information about the in-cylinder pressure sampled with 0.1 CAD. No modifications were done to the original water cooling system. The water temperature was $95^{\circ} \mathrm{C}$. The operating conditions of the CFR engine are presented Table 2.

Table 2. Engine specifications and operating conditions

\begin{tabular}{|l|l|}
\hline Engine Type & Single Cylinder CFR \\
\hline Injection System & Port Fuel Injection \\
\hline Bore & $82.55 \mathrm{~mm}$ \\
\hline Stroke & $114.3 \mathrm{~mm}$ \\
\hline Connecting Rod & $254 \mathrm{~mm}$ \\
\hline Compression ratio & Variable from $4: 1$ to $15: 1$ \\
\hline Speed & $600-900 \mathrm{rpm}$ \\
\hline Spark timing (ST) & $-13 \mathrm{CAD}(\mathrm{Crank}$ Angle Degree) \\
\hline Minimum Intake Air Temperature & $52 \pm 2{ }^{\circ} \mathrm{C}$ \\
\hline Maximum Intake Air Temperature & $149 \pm 2{ }^{\circ} \mathrm{C}$ \\
\hline Lambda $(\lambda)$ & $1(\mathrm{SI})$ or $3(\mathrm{HCCI})$ \\
\hline
\end{tabular}

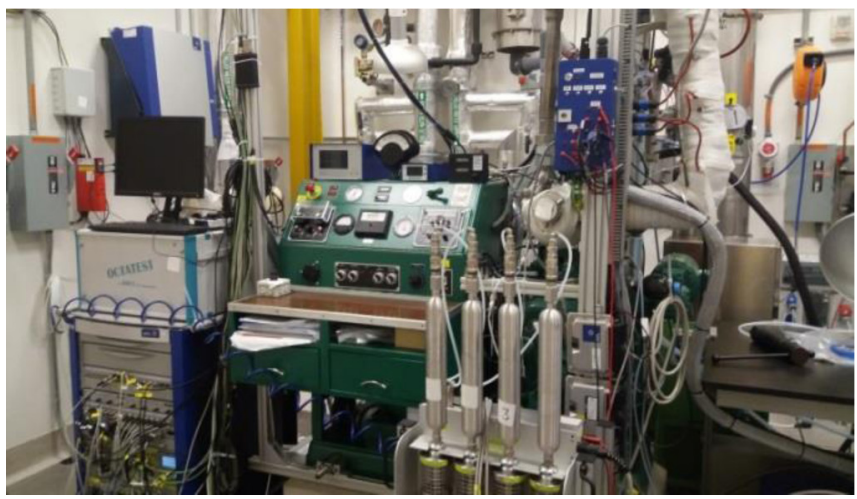

Figure 1. CFR engine

\section{IQT-Experiment}

The IQT is a standard test device to measure derived cetane number (DCN) according to ASTM D6890 [이․ The IQT is equipped with a constant volume combustion chamber of volume $0.21 \mathrm{~L}$ that is filled with zero air $(20.9 \pm 1.0 \%$ O2 and $79 \%$ Nitrogen with negligible amounts of hydrocarbons and water) pressurized to $2.137 \pm 0.007$ $\mathrm{MPa}$ and heated to a standard temperature as explained below. Figure $\underline{2}$ shows the ignition quality tester. The standard temperature is determined by adjusting the temperature so 3 runs of n-heptane provides an ignition delay of $3.78 \pm 0.01 \mathrm{~ms}$. Ignition delay of fuels is then measured from the pressure trace obtained by injecting a liquid fuel into pressurized and heated air. An IQT is ideally designed to measure ignition of diesel-like (high reactivity) fuels, however for gasoline-like (low reactivity) fuels, the gradient method described in can be applied [40]. All ignition delay values in the present study are obtained with the gradient method. The method is based on the pressure signal. It involves the determination of the point of intersection of two line tangents (LT): one LT at the pressure recovery point, the point where the pressure regains initial chamber pressure that dropped due to evaporative cooling; the other LT being the maximum slope during combustion pressure rise [40].

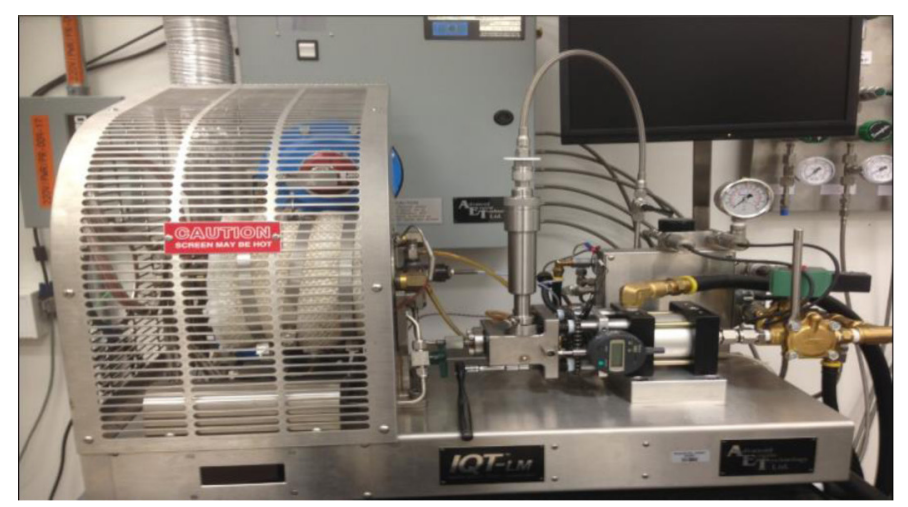

Figure 2. IQT apparatus

\section{Fuels}

Three FACE (Fuel for advanced combustion engines) gasolines, specifically FACE I, FACE J and FACE A were used for the study. Details on some of the properties and the concentration of aromatics and n-paraffin's in the FACE fuels are given in the Table 3. The PRF mixtures corresponding to RON of 70 and 84 were also tested. 
Ethanol with concentration by volume of $0 \%, 2 \%, 5 \%, 10 \%, 15 \%$ and $20 \%$ was added to the FACE fuels and PRF. The total fuel blends for FACE gasolines and PRF solutions were 18 and 12, respectively. In total, 30 blends were tested in SI, HCCI and in IQT. More details about the fuel blends can be found in Appendix- A.

Table 3. FACE Fuels and their properties

\begin{tabular}{|l|l|l|l|l|l|}
\hline $\begin{array}{l}\text { Fuel } \\
\text { Designation }\end{array}$ & $\begin{array}{l}\text { FACE } \\
\text { I }\end{array}$ & $\begin{array}{l}\text { FACE } \\
\text { J }\end{array}$ & $\begin{array}{l}\text { FACE } \\
\text { A }\end{array}$ & $\begin{array}{l}\text { PRF } \\
\mathbf{7 0}\end{array}$ & $\begin{array}{l}\text { PRF } \\
\mathbf{8 4}\end{array}$ \\
\hline RON & 70.3 & 71.8 & 83.5 & 70 & 84 \\
\hline MON & 69.6 & 68.8 & 83.6 & 70 & 84 \\
\hline Sensitivity & 0.7 & 3.0 & -0.1 & 0 & 0 \\
\hline $\begin{array}{l}\text { Aromatic } \\
(\%)\end{array}$ & 5.0 & 35.0 & 5.0 & 0 & 0 \\
\hline $\begin{array}{l}\text { N-Paraffin's } \\
(\%)\end{array}$ & 5.0 & 25.0 & 5.0 & 30 & 16 \\
\hline
\end{tabular}

\section{OCTANE NUMBER (ON) OF BLENDS}

\section{Research Octane Number}

The Research and Motor octane number (RON and MON respectively) are used to characterize the autoignition properties of the fuel in the SI engines [25]. The scale of RON and MON are based on two paraffinic hydrocarbons: Iso-octane defines the maximum limit of the scale with a value of 100 , and n-heptane defines the minimum limit of the scale with a value of 0 [25]. Although, it is possible to have fuels beyond 100 octane number. For fuels with octane numbers above 100 , the scale is extrapolated through the addition of dilute tetraethyl lead (TEL) to iso-octane based on an empirically determined relationship [41]. This extends the octane number scale to its maximum value of 120.3. Blends of iso-octane and $n$-heptane are referred to as primary reference fuels (PRFs). A PRF65 refers to RON of 65 with iso-octane percentage of $65 \%$ and $35 \%$ of n-heptane by volume. The RON and MON are measured in a standardized single cylinder Cooperative Fuel Research (CFR) engine using ASTM standard tests $[\underline{41}, \underline{42}]$. The RON is obtained by running the CFR at $600 \mathrm{rpm}$, with an inlet air temperature of $52^{\circ} \mathrm{C}$ and constant spark timing of $13^{\circ}$ before top dead center (bTDC). The compression ratio is adjusted until trace knock is detected. Since the CFR engine for this study was modified, RON for the fuel blends were obtained by determining the transfer function for PRFs ranging from 70 to 100 . The transfer function for this study is defined as the conversion procedure of the compression ratio readout to the mixture of iso-octane and n-heptane. Figure 3 show the compression ratio for trace knock obtained in SI combustion mode with PRFs. Figure 4 illustrates the procedure followed to obtain the compression ratios for different PRF mixtures for the transfer function in the SI mode. A knock criteria of peak to peak pressure fluctuations of 2 bar \pm 0.02 for a moving window of 188 cycles was set to determine the compression ratio. For all fuel blends, the compression ratio was adjusted until peak to peak pressure fluctuation of 2 bar was obtained. A lambda sweep was then performed to confirm that the lambda for maximum knock was used.

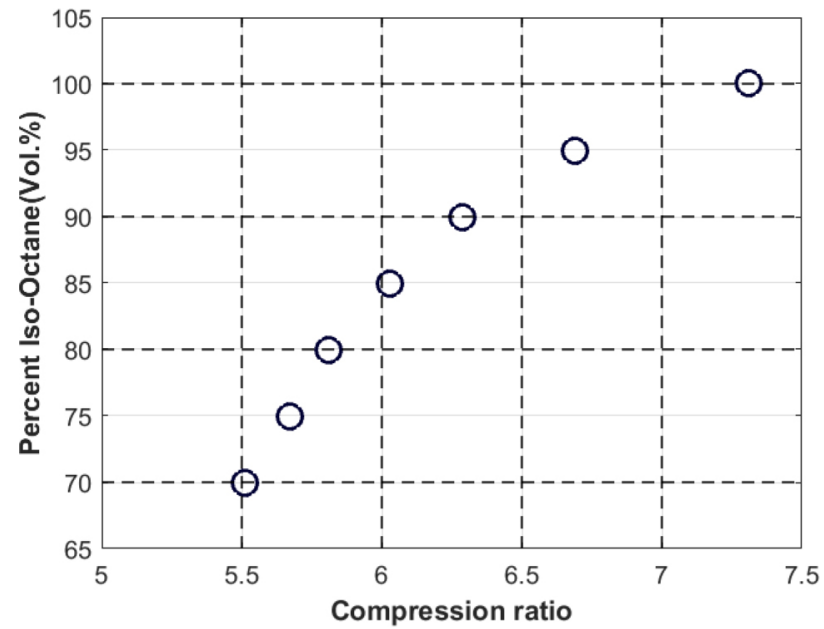

Figure 3. Transfer function in SI mode, $600 \mathrm{rpm}, 52^{\circ} \mathrm{C}, \mathrm{ST}=-13, \lambda=1$

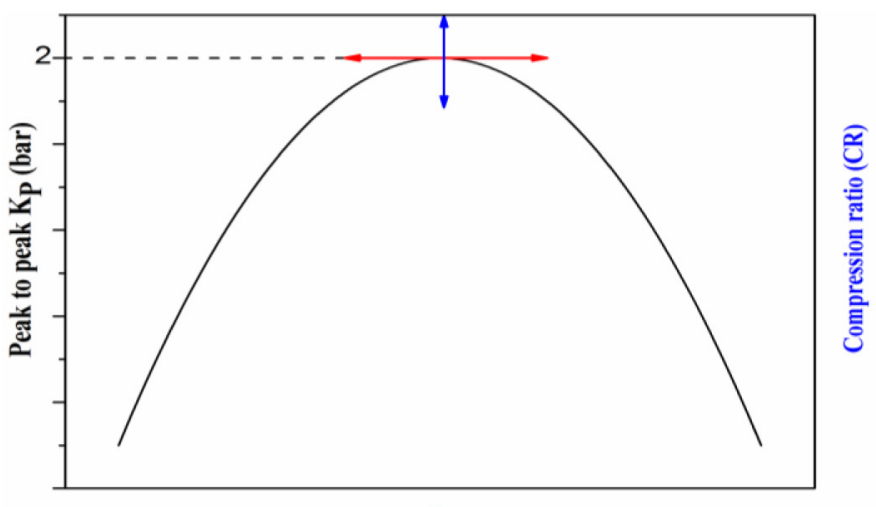

$\lambda$

Figure 4. Knock criteria (K p) for compression ratio

A line of fit in the form of quadratic was obtained from Figure 3 . The equation was in the form:-

$$
R O N=a R_{C}^{2}+b R_{C}+c
$$

Where $R O N$ represented the percentage of iso-octane by volume in the Primary reference fuel mixture and $R_{c}$ was the compression ratio. The coefficients of the equations were $\mathrm{a}, \mathrm{b}$ and $\mathrm{c}$ and their constant values are given in Appendix A in Table A3. The fuel blends were tested and the compression ratio obtained was used in equation 1 to estimate RON of the fuel blends.

\section{Homogeneous Charge Compression Ignition (HCCI) Fuel Number}

It was identified that RON and MON are not sufficient to characterize the auto-ignition behavior of the fuel in HCCI operating conditions [26]. The Lund-Chevron HCCI number was developed to understand the auto-ignition behavior of the fuel in HCCI mode [26]. The procedure for determining HCCI fuel numbers requires finding the compression ratio for the auto-ignition of tested fuel with a CA50 (Crank Angle for $50 \%$ heat release) of $3^{\circ}$ after TDC. Similar to SI mode, a transfer function plot was obtained by autoigniting different mixtures of Primary Reference Fuels (PRFs). Figure 5 shows the obtained transfer function for all the four HCCI conditions. 


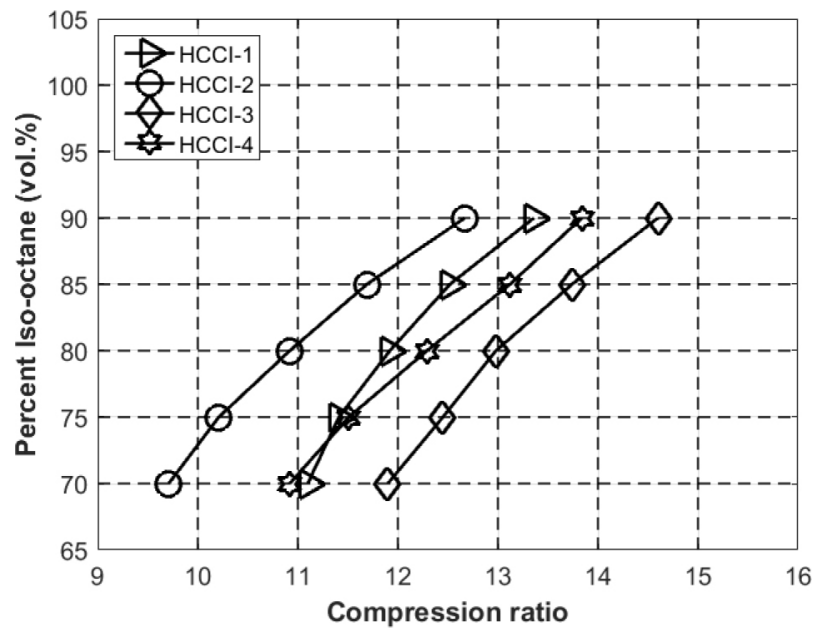

Figure 5. Transfer function in HCCI mode for four HCCI operating conditons, $\lambda=3$

A line of best fit was obtained for all the four conditions. The line of best fit was in the form of quadratic equation given by:-

$$
\text { HCCI fuel number }=p R_{c}^{2}+q R_{c}+r
$$

Where HCCI fuel number represented the percentage of iso-octane by volume in the Primary Reference Fuel mixture and $R_{c}$ was the compression ratio. The coefficients of the equations were $p, q$ and $r$ and their constant values are given in Appendix A in Table A4. The FACE fuel blends were tested in HCCI mode and the required compression ratios for the autoignition of the blends were used alongside equation 2 to estimate the HCCI fuel number.

\section{Blending Octane Number (BON)}

The non-linear response of RON with ethanol addition has given rise to the so-called blending octane number. The octane number of ethanol is 108 and if there were no non-linear effects, then the blending octane number would be constant and equal to the pure component octane number [1]. A higher blending octane number means that on a per unit volume basis, the ethanol provides more anti-knock resistance.

The blending octane number $(\mathrm{BON})$ was expressed in terms of base fuel RON (for the present study, FACE fuels and PRF solutions at $0 \%$ ethanol), the concentration of the base fuel, the booster concentration (for the present study, ethanol) and the blending RON(BRON) [1, 12]. For the case of SI mode, BON can be expressed as:

$$
R O N_{\text {base }} \cdot C_{\text {base }}+\text { BON. } C_{\text {booster }}=R O N_{\text {mix }}
$$

Where

$R O N_{\text {base }}=\mathrm{RON}$ of the base fuel

$C_{\text {base }}=$ Concentration of the base fuel

$C_{\text {booster }}=$ Concentration of the booster
$R O N_{\text {mix }}=$ Octane numbers of the blends $(2 \%, 5 \%, 10 \%, 15 \%, 20 \% \mathrm{vol}$.

For HCCI mode, equation 3 can be expressed as:-

$$
\text { HCCI base } \cdot C_{\text {base }}+\text { BON. } C_{\text {booster }}=H C C I_{\text {mix }}
$$

Where

$H_{C C} I_{\text {base }}=\mathrm{HCCI}$ fuel number for the base fuel ( $0 \%$ ethanol)

$C_{\text {base }}=$ Concentration of the base fuel

$C_{\text {booster }}=$ Concentration of the booster

$H C C I_{\text {mix }}=\mathrm{HCCI}$ fuel numbers of the blends $(2 \%, 5 \%, 10 \%, 15 \%$, 20\%vol.)

\section{Blending Derived Cetane Number (BDCN)}

Derived cetane number (DCN) of the fuel samples are calculated based on the ignition delay range; i.e., for values of 3.1 to $6.5 \mathrm{~ms}$ equation 5 is used [40], while for values outside this range eq. 6 is used [눙]

$$
\begin{gathered}
D C N=4.46+\left(\frac{186.6}{\tau_{i d}}\right) \\
D C N=83.99\left[\left(\tau_{i d}-1.512\right)^{-0.658}\right]+3.547
\end{gathered}
$$

Where

$\tau_{i d}=$ Total ignition delay time

For CI mode, equation 3 can be expressed as:-

$$
D C N_{\text {base }} \cdot C_{\text {base }}+B D C N . C_{\text {booster }}=D C N_{\text {mix }}
$$

Where

$D C N_{\text {base }}=$ Derived Cetane Number for the base fuel ( $0 \%$ ethanol)

$C_{\text {base }}=$ Concentration of the base fuel

$C_{\text {booster }}=$ Concentration of the booster

$D C N_{\text {mix }}=$ Derived Cetane Number of the blends $(2 \%, 5 \%, 10 \%, 15 \%$, $20 \%$ vol.)

$B D C N=$ Blending Derived Cetane Number 


\section{RESULTS}

\section{SI Results}

\section{FACE I, FACE J and FACE A}

The three FACE fuels were blended with ethanol and tested in the modified CFR engine. Ethanol with concentration by volume of 2, 5, 10,15 and 20 percent was added to the FACE fuels. Figure 6 and $\underline{7}$ shows the compression ratio and the change in the RON of the three FACE fuels with the ethanol addition.

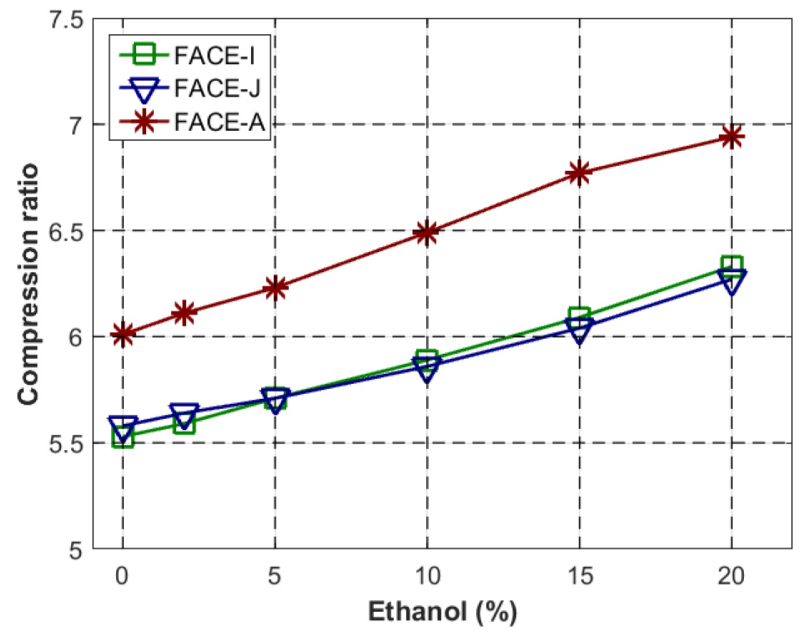

Figure 6. Compression ratios for FACE fuels in SI mode, $600 \mathrm{rpm}, \mathrm{T}_{\text {in }}=52^{\circ} \mathrm{C}$, $\mathrm{ST}=-13 \mathrm{CAD}, \lambda=1$

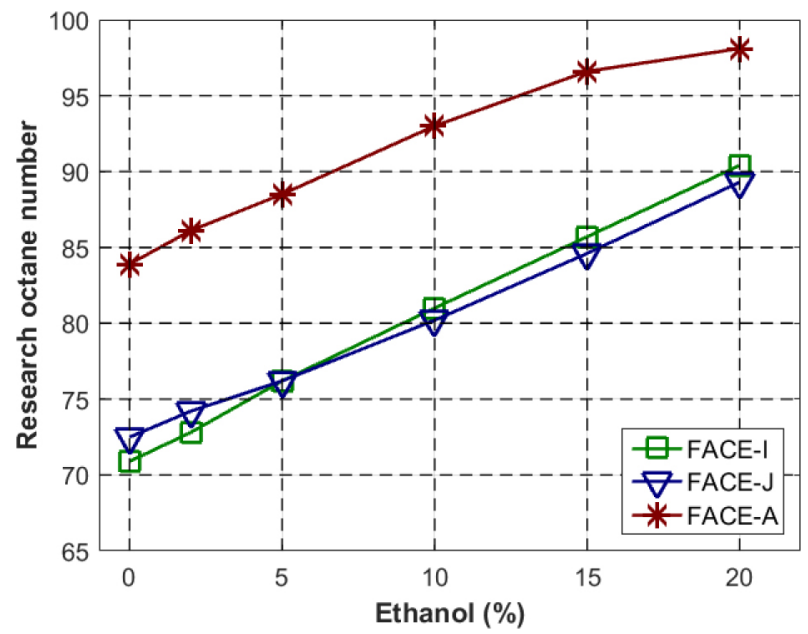

Figure 7. RON of FACE I, J and A with ethanol concentration in SI mode, 600 rpm, $\mathrm{T}_{\text {in }}=52^{\circ} \mathrm{C}, \mathrm{ST}=-13 \mathrm{CAD}, \lambda=1$

The results show that the RONs of FACE I and FACE J changed from around 70 to 90 and were linearly varying with the addition of ethanol up to the maximum tested $20 \%$. The blending RON for FACE I blends (5\% aromatics) are slightly lower for $2 \%$ ethanol when compared with FACE J (35\% aromatics). However, beyond concentration of $5 \%$, the blending RON for Face I is slightly higher. This is consistent with the findings of Silva et al which showed that blends with low aromatic contents ( $9 \%$ vs $43 \%$ ) had significantly higher blending RON with $25 \%$ ethanol addition [43]. The change in RON for FACE A was from 84 to 97 with $20 \%$ ethanol addition. The RON of FACE A blends increased linearly up to concentrations of
$10 \%$ ethanol. However, beyond concentrations of $10 \%$ ethanol the RON behavior became saturated. Foong at al also observed nearsaturated behavior for gasoline blends with high ethanol concentrations [녀].

Figure 8 presents the blending octane number for three FACE fuels with the addition of Ethanol. The BON was higher than the RON of pure ethanol and hence non-linear effects are present. The blending octane number for all three FACE fuels was in the range of 140 to 200. The three FACE fuels were observed to behave non-linearly with the increasing ethanol concentration. The octane enhancement effect of ethanol on FACE I was lower at 2\% ethanol and then rather constant from 5 to $20 \%$. The octane enhancement effect on FACE J was lowest for ethanol concentrations of 2 to $15 \%$ due to the higher aromatic contents of the base fuel. A decaying behavior with the increase of ethanol concentration was observed for FACE A which has a higher base RON. The BON behavior for FACE I and FACE A is similar between $5 \%$ and $15 \%$ ethanol concentrations followed by a sharp decrease for FACE A after 15\%. Rankovic et al have shown that for the base fuel with RON 71 and 91, the BON behaved differently and higher BON was observed for RON 71 base fuel [12]. Both FACE I and FACE A have 5\% aromatic concentration but FACE A has RON of 83.5 higher than FACE I which has a RON of 70.3, so it was expected that BON behavior will be different. It is difficult to conclude that BON does not depend on octane number of the base fuel, but it could be the case that FACE A with RON 83.5 is not sufficient to indicate the dependency of octane number on BON as previously highlighted by Rankovic et al [12].

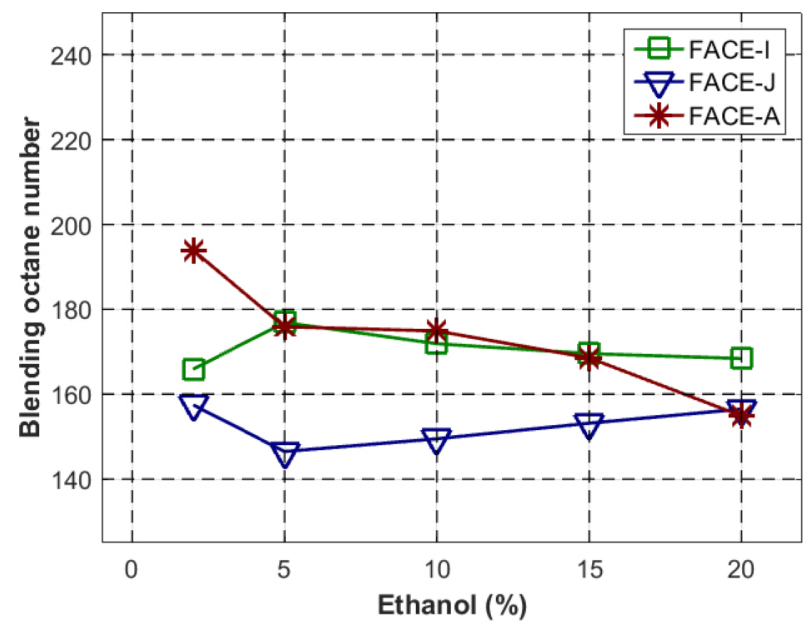

Figure 8. Blending octane number for FACE I, J and A with ethanol concentration in SI mode, $600 \mathrm{rpm}, \mathrm{T}_{\mathrm{in}}=52^{\circ} \mathrm{C}, \mathrm{ST}=-13 \mathrm{CAD}, \lambda=1$

\section{HCCI Results}

\section{FACE I, FACE J, FACE A, PRF70 and PRF84}

In addition to the three FACE fuels, PRF70 and PRF84 were also tested in HCCI mode. FACE I and FACE J had a RON close to 70, and therefore PRF70 was blended with ethanol for comparison purposes. The same applies for the selection of PRF84 which is close to the RON of FACE A. As discussed in previously, the RON is not 
an ideal indicator of the fuel autoignition characteristics for HCCI operating conditions. As such, the HCCI fuel number will be used to describe the performance of FACE fuels and PRFs in this section

Figure 9 presents the variation of HCCI fuel number-1 with ethanol concentration for an engine speed of $600 \mathrm{rpm}$ and inlet air temperature of $52^{\circ} \mathrm{C}$ corresponding to RON conditions. HCCI- 1 in the legend is used to show the operating condition in HCCI mode in terms of speed and inlet air temperature. More details about the definition of four HCCI numbers specifically defined for this study can be found in the introduction section. For neat ethanol, the HCCI number will be equal to the RON of the fuel as mixtures of iso-octane and n-heptane are used to define the scale in both cases. For ethanol concentrations up to $5 \%$, it can be observed that the change in the HCCI number is approximately the same for all FACE fuels. Among the low RON fuels, FACE J had a slightly different slope than FACE I and PRF70.

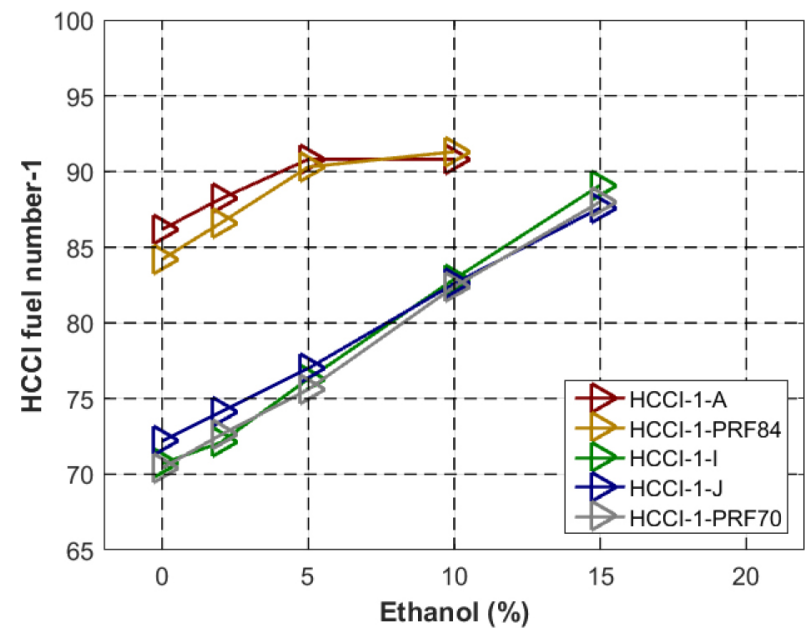

Figure 9. HCCI fuel number for FACE fuels, PRFs at $600 \mathrm{rpm}, \mathrm{T}_{\text {in }}=52^{\circ} \mathrm{C}$ and $\lambda=3$

Figure 10 presents the blending octane numbers for all three FACE fuels and PRF70 and PRF84. The overall BON level for the low octane fuels was 140 to 190 . The blending octane numbers for FACE I, FACE J and PRF70 were observed to be lower than FACE A and PRF84 at low ethanol concentrations but with the increasing concentration, a sharp decrease in the BON for FACE A and PRF 84 occurred.

It was observed that FACE $\mathbf{J}$ with a higher aromatic content has a lower BON than FACE I. This trend is consistent with the SI tests (Figure 8). Overall, ethanol had a strong octane enhancement effect on the fuels with high RON at low ethanol concentration, e.g. FACE A and PRF84. The BON is in the range of 130 to 210 for the higher octane fuels (ON 84). The octane enhancement of ethanol on PRF84 was stronger than FACE A with the BON difference of about 20 units.

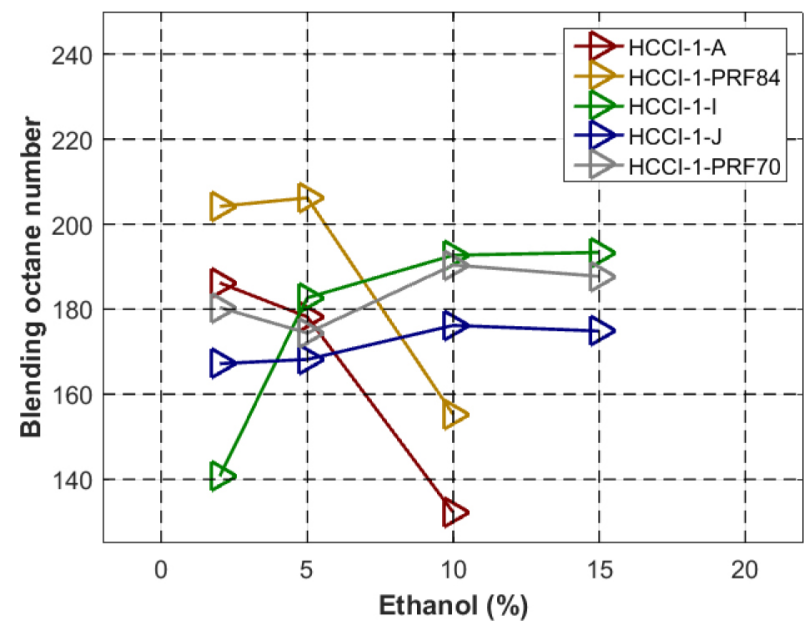

Figure 10. Blending octane number for FACE fuels, PRFs at $600 \mathrm{rpm}, \mathrm{T}_{\text {in }}=$ $52^{\circ} \mathrm{C}$ and $\lambda=3$

Figure 11 presents the plot of the BON when the engine speed was kept constant at $600 \mathrm{rpm}$, with an inlet air temperature increased to $149^{\circ} \mathrm{C}$. The plot for HCCI fuel number for this case is presented in the Appendix B.

The overall BON level was in the range of 130 to 210.The BONs are more strongly influenced by the inlet air temperature than the engine speed. For the case of the 70 RON fuels, PRF 70 and FACE I showed somewhat a similar trend whereas FACE J had the lowest BON among the 70 RON fuels. Both FACE J and FACE I had RONs close to 70 but the plot shows a different octane enhancement effect for both fuels. This indicates that the fuel composition contribute towards the observed behavior.

Both FACE A and PRF84 exhibit large negative slopes similar to what was observed for an intake temperature of $52^{\circ} \mathrm{C}$ and speed of $600 \mathrm{rpm}$. A PRF84 had higher BON values than the other fuels for ethanol concentrations of up to $5 \%$.

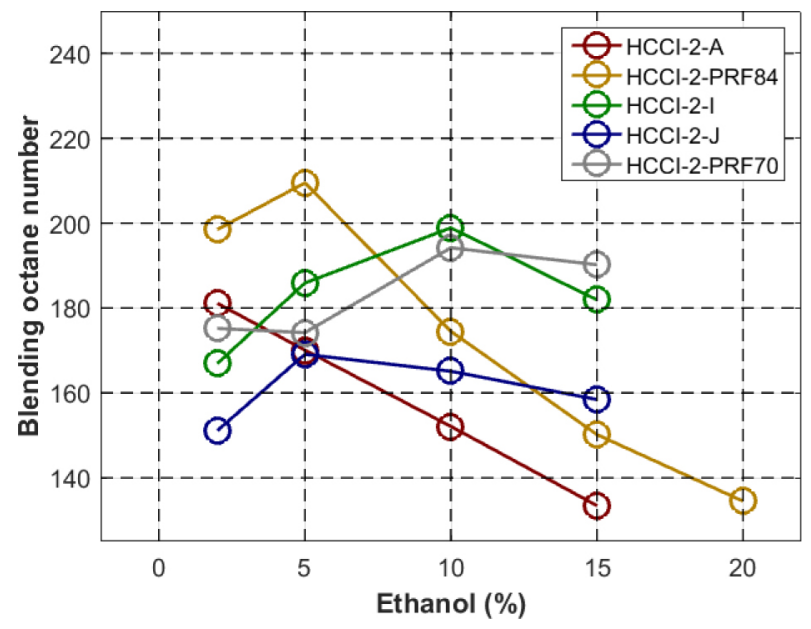

Figure 11. Blending octane number for FACE fuels and PRFs at $600 \mathrm{rpm}, \mathrm{T}_{\text {in }}$ $=149^{\circ} \mathrm{C}$ and $\lambda=3$ 
Figure 12 presents the plot of blending octane number when the engine speed was increased to $900 \mathrm{rpm}$ with the inlet air temperature held constant at $52^{\circ} \mathrm{C}$. The HCCI fuel number plot for this case is presented in Appendix B.

The overall BON level for the low octane fuel (ON 70) was 170 to 218. A PRF70 had a high blending octane numbers with up to $10 \%$ ethanol addition. The change in engine speed also has an improved octane enhancement effect on PRF70. It was observed that FACE J still has the lowest BON with the exception of $5 \%$ ethanol concentration. However, the limited number of data points for FACE A and PRF84 made it difficult to establish how the octane enhancement effect of ethanol will work for these high RON fuels with increasing ethanol concentration. The BON level for the high octane fuels was 165 to 190 . However it can be observed that compared to the case when the engine speed was $600 \mathrm{rpm}$ and inlet air temperature was $52^{\circ} \mathrm{C}$, the octane enhancement effect of ethanol on FACE A and PRF 84 has weakened for all concentrations of ethanol. This effect was more considerably noticed for PRF84 than FACE A. This observation is not true for the case of FACE I and FACE J, which have shown an improvement in the BON as the speed is increased. Overall, the difference between the low octane and high octane number base fuels increase at an engine speed of $900 \mathrm{rpm}$.

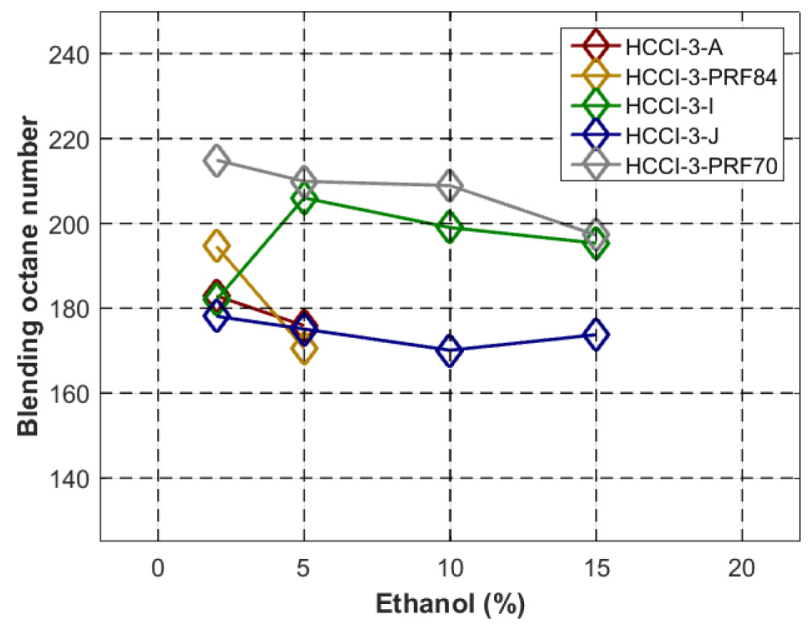

Figure 12. Blending octane number for FACE fuels and PRFs at $900 \mathrm{rpm}, \mathrm{T}_{\text {in }}$ $=52^{\circ} \mathrm{C}$ and $\lambda=3$

Figure 13 presents the combined effect of high intake temperature and engine speed, which corresponds to MON conditions of SI tests ( $900 \mathrm{rpm}$ and $149^{\circ} \mathrm{C}$ respectively). The plot for HCCI number for this case is presented in Appendix B.

The overall BON levels for the low and high octane fuels were 160 to 240 and 110 to 250 respectively. Hence Figure 13 is using a different scale than Figure 10 to 12 for HCCI number 1 to 3 . The combined effect of high engine speed and intake temperature suggests that ethanol was most effective for the low octane fuels. It can be observed that FACE I, FACE J and PRF70 had higher BONs in comparison with FACE A and PRF84, with the exception of low ethanol concentrations. The PRF 70 showed a positive slope at low ethanol concentrations followed by negative slope at high concentrations. At low concentrations of ethanol, PRF84 shows the highest BON. However, as ethanol concentration increases, this enhancement effect is diminished. A particularly strong negative slope was observed for PRF84 while FACE A had the lowest BON values and the slope was also comparatively low. It could be noted that the blending octane number with $15 \%$ ethanol and FACE A as base fuel is reaching that of pure ethanol i.e. there is no longer any nonlinear blending effect of the ethanol.

It was observed that negative slope existed for high RON 84 fuels and positive or constant slope existed for the RON 70 fuels for all HCCI numbers except for HCCI-4 condition. That could be due to different ethanol effect on fuels with different base RONs. The slopes for the BON became steeper in the case of HCCI-4 compared to HCCI-1 which was expected because as the inlet temperature increases, ethanol becomes comparably more reactive, owing to its higher octane sensitivity [ $\underline{38}]$. The higher sensitivity results ethanol being less effective as an octane improver as the inlet temperature and in-cylinder temperature increase, and hence steeper slopes for BON were observed.

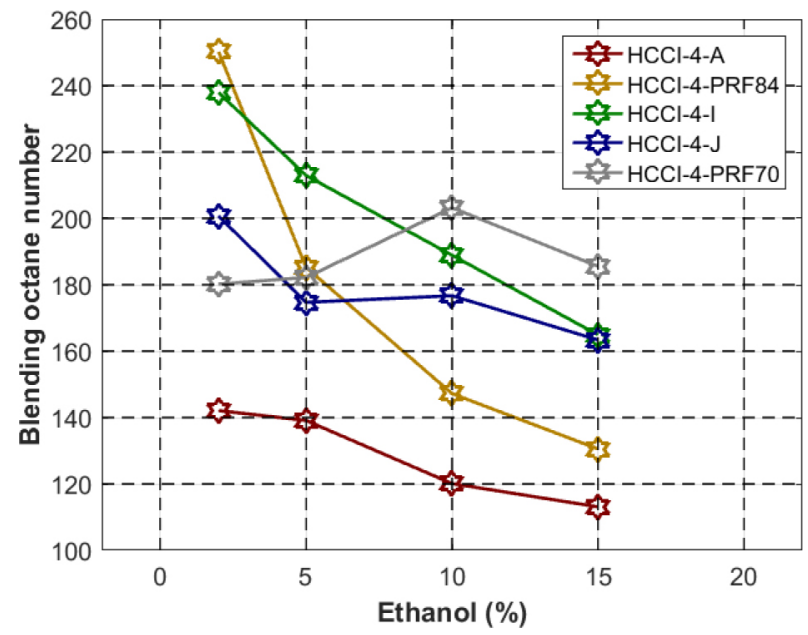

Figure 13. Blending octane number for FACE fuels and PRFs at $900 \mathrm{rpm}, \mathrm{T}_{\text {in }}$ $=149^{\circ} \mathrm{C}$ and $\lambda=3$

\section{Effect of Speed and Temperature}

The same data in Figure 10 to $\underline{13}$ will now be presented for one fuel at a time to see the effect of operating conditions such as engine speed and inlet air temperature more clearly. The previous section highlighted that the performance comparison for fuels with RON 70 (FACE I, FACE J, PRF 70) against fuels with RON 84 (FACE A and PRF84) at different engine speeds and inlet air temperatures. It was found that all the fuels did not behave the same. The engine speed and inlet air temperature were found to be critical in determining under which conditions ethanol will have the strongest octane enhancement effect.

$\underline{\text { Figures } 14}, \underline{15}$ and $\underline{16}$ presents the BON for the FACE I, FACE J and PRF70 respectively. The HCCI fuel number plots for all three fuels are presented in the Appendix B.

The operating conditions had large effect on FACE I. At an engine speed of $600 \mathrm{rpm}$ and intake temperature of $52^{\circ} \mathrm{C}$, the BON for FACE I increases with the ethanol concentration. With the combined high speed of $900 \mathrm{rpm}$ and inlet air temperature of $149^{\circ} \mathrm{C}$, the BON goes 
down with the increasing ethanol concentration. The two other intermediate operating conditions for FACE I are less responsive. The four operating conditions did not have much effect on FACE $\mathrm{J}$ and PRF70 with their behavior somewhat similar.

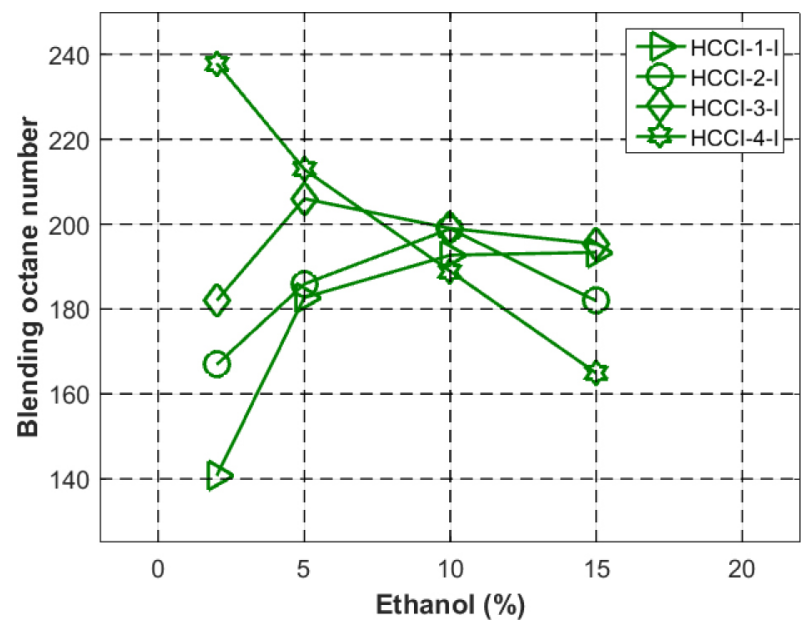

Figure 14. Blending octane number for FACE I, $\lambda=3$

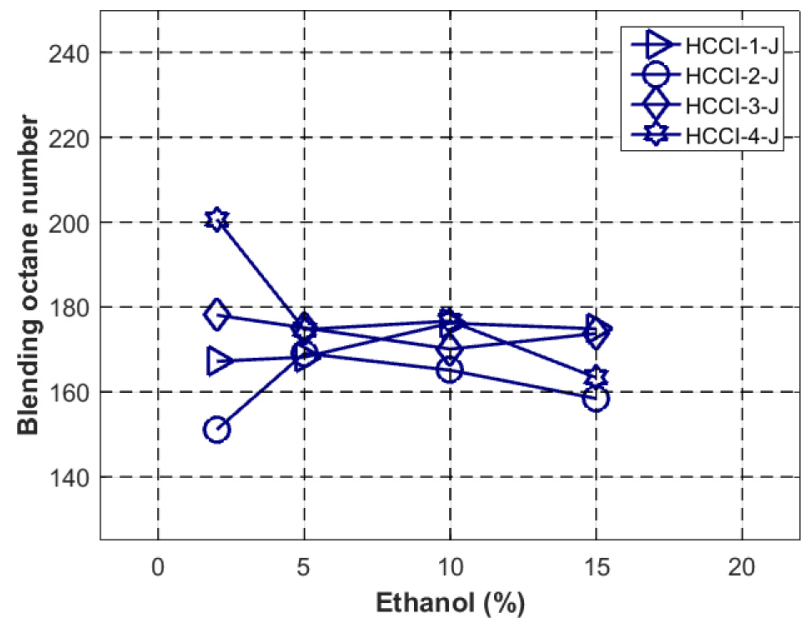

Figure 15. Blending octane number for FACE J, $\lambda=3$

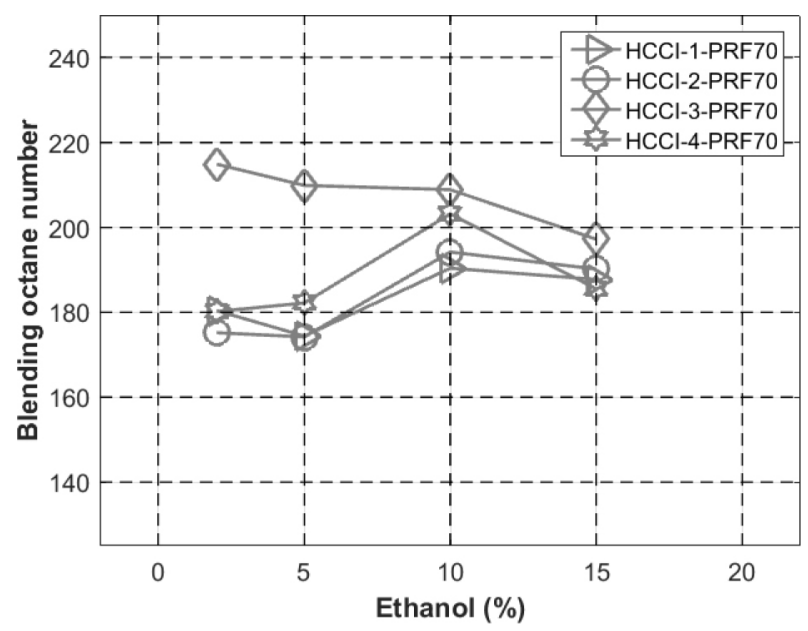

Figure 16. Blending octane number for PRF70, $\lambda=3$
Figures 17 and $\underline{18}$ presents the BON for FACE A and PRF84 respectively. The plots for HCCI fuel number for these two fuels are presented in Appendix B.

The four operating conditions caused far less changes on FACE A than FACE I. The BON for FACE A reduced considerably at an engine speed of $900 \mathrm{rpm}$ and intake temperature of $149^{\circ} \mathrm{C}$ than FACE I with $15 \%$ ethanol the BON of FACE A almost approaching RON of ethanol. The response for PRF84 was not same as PRF70. The higher intake temperature provided a much higher BON slope for both speeds in a similar sense as FACE A. It was also observed that FACE I and FACE A were more strongly influenced by the increase in engine speed and the intake temperature. Overall, for RON84 fuels a steeper slope is observed for both Face A and PRF84 in all HCCI conditions.

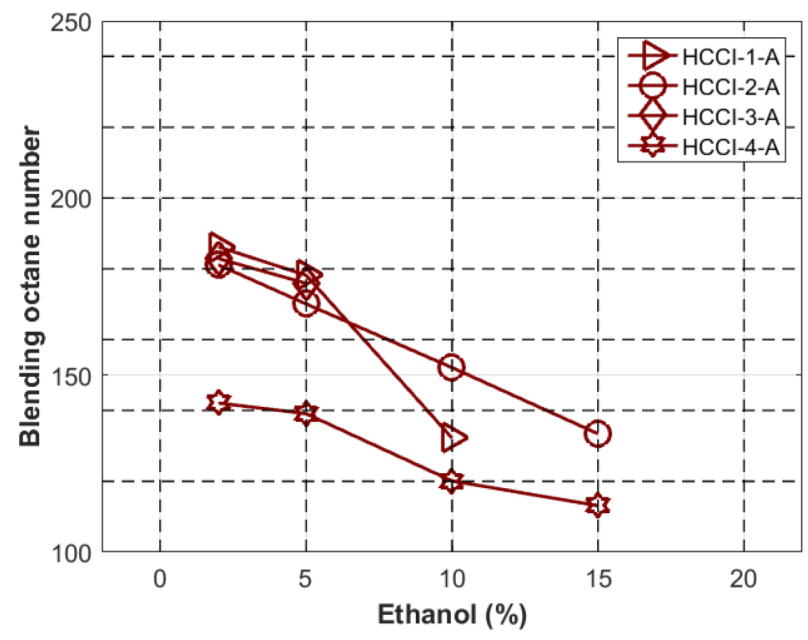

Figure 17. Blending octane number for FACE A, $\lambda=3$

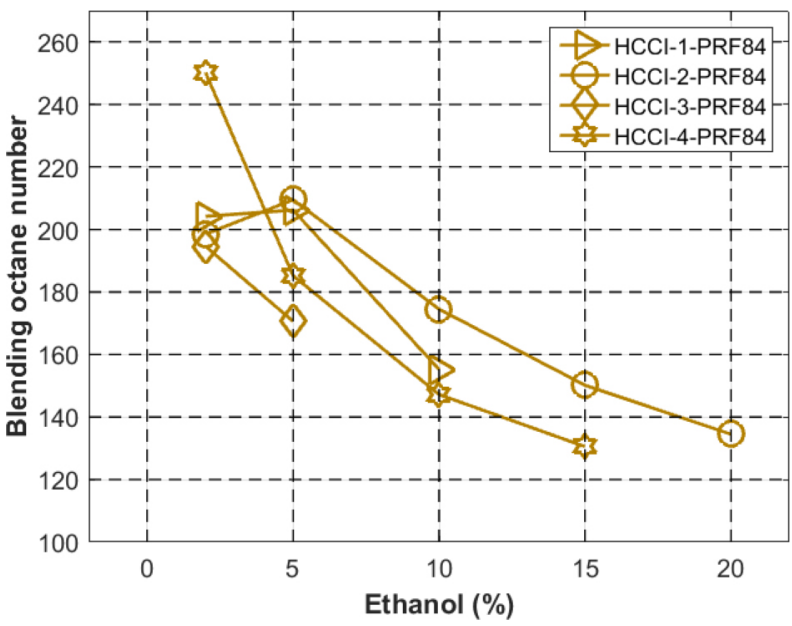

Figure 18. Blending octane number for PRF84, $\lambda=3$

\section{IQT RESULTS}

$\underline{\text { Figures } 19}$ and $\underline{20}$ present the total ignition delay times and derived cetane numbers (DCN), respectively, for all the fuels used in the present study. As can be observed the total ignition delay time increases monotonically with increase in ethanol concentrations. FACE I, FACE J, and PRF70 have their RON close to 70 and likewise their ignition delay times are also in agreement $(\sim 7 \mathrm{~ms})$ as 
seen in Figure 19. At $20 \%$ ethanol concentrations ignition delay time of FACE J increased by $68 \%$, followed by $87 \%$ increase for FACE I, $116 \%$ for PRF 70. Similarly, FACE A and PRF84 that have RON 84 have their total ignition delay times identical ( $~ 8.5 \mathrm{~ms})$. An increase of $122 \%$ in ignition delay time was observed for FACE A and $148 \%$ for PRF 84 with 20\% ethanol.

The corresponding DCN for these fuels decreases linearly as shown in Figure 20 with ethanol addition. The FACE J which has higher aromatic content had a slightly higher total ignition delay time at lower concentrations of ethanol than FACE I leading to lower DCNs. A PRF70 behaved similar to FACE I at all concentrations. Addition of $20 \%$ ethanol reduced DCN of FACE J, FACE I and PRF 70 by 30 , 35 and $40 \%$ respectively. FACE A and PRF84 having high octane number had longer ignition delay time and consequently lower, DCNs as expected. The variation in DCN of FACE A and PRF84 with ethanol addition was the same a reduction in $40 \%$ of DCN at $20 \%$ ethanol concentration.

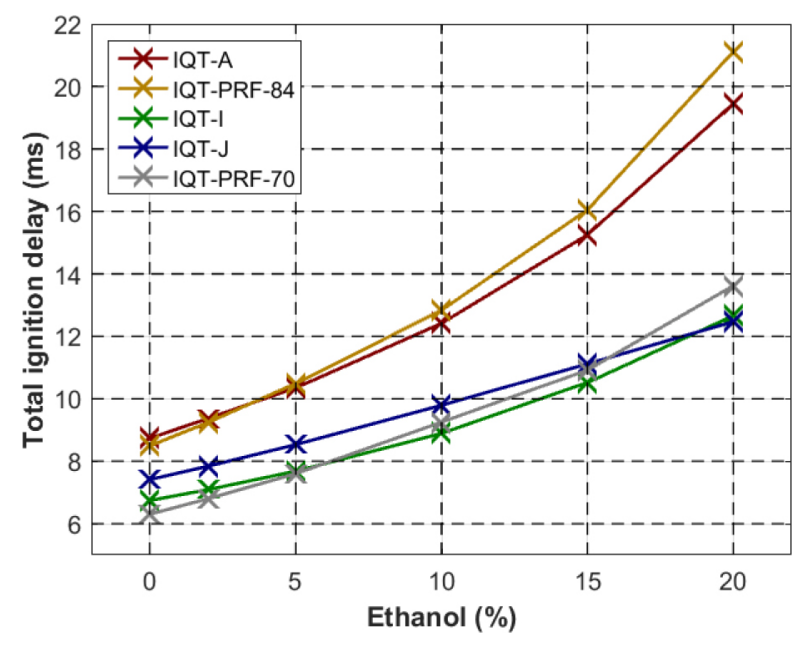

Figure: 19. Total ignition delay time for all five fuels

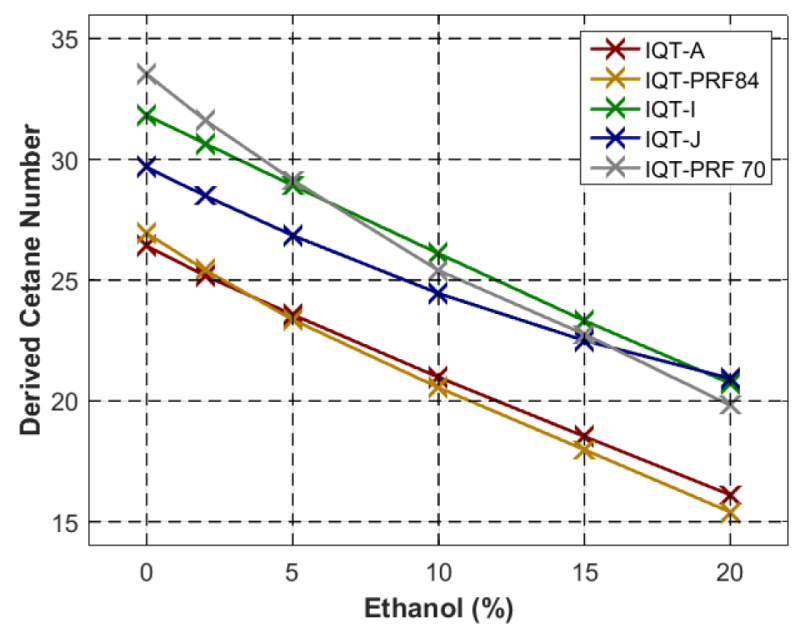

Figure 20. Derived Cetane number (DCN) for all ethanol blends
Figure 21 presents the BDCN of ethanol with different base fuels calculated with Eq. 7. It should be noted that the BON for $2 \%$ ethanol concentration showed higher values in the SI tests (Figure 8) for FACE I than FACE J opposite to what is observed here. The FACE gasoline with higher aromatic contents i.e. FACE J had a higher BDCN than FACE I showing a weak octane enhancement effect from ethanol. A PRF70 with the lowest BDCN showed a reduction in the reactivity. Both FACE I and FACE A showed a similar behavior for all ethanol concentrations except at $2 \%$ ethanol concentrations. This is consistent with the behavior observed in BON for FACE I and FACE A in SI tests (Figure 8). When ethanol is blended with FACE A the change in BDCN is lesser compared to PRF 84 and both of them followed a same slope.

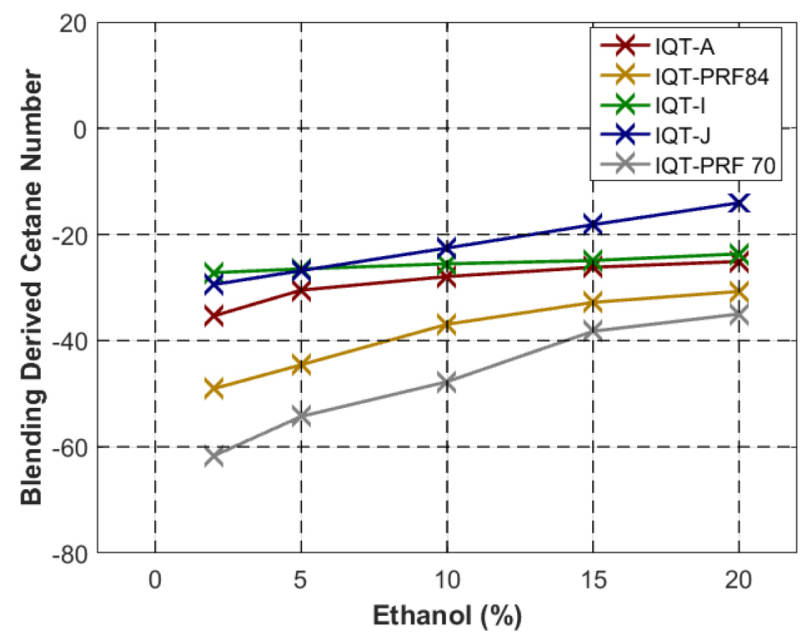

Figure 21. Blending Derived Cetane number for five fuels

\section{CORRELATION BETWEEN SI, HCCI AND IQT}

\section{SI vs HCCI}

$\underline{\text { Figures } 22}, \underline{23}$ and $\underline{24}$ presents the blending octane number performance for HCCI against SI for FACE I, FACE J and FACE A respectively. Both FACE I and FACE J had higher blending octane numbers for HCCI than SI for ethanol concentrations of 5-15\%. Different trends for FACE I and FACE J could be due to different aromatic concentrations. The higher BON-HCCI for 70 RON fuels suggest that lean auto-ignition behaved differently and had stronger effect compared to stoichiometry combustion. It could be observed that for FACE A, the blending octane numbers were about the same for both SI and HCCI modes at 5\% ethanol concentration resulting in similar behavior for lean and stoichiometry auto-ignition. As the ethanol concentration was increased from $5 \%$ to $10 \%$, the blending octane number was higher for SI mode. The high BON-SI for FACE A could be due to the non-linear effect in terms of heat of evaporation since more fuel is utilized in SI mode. 


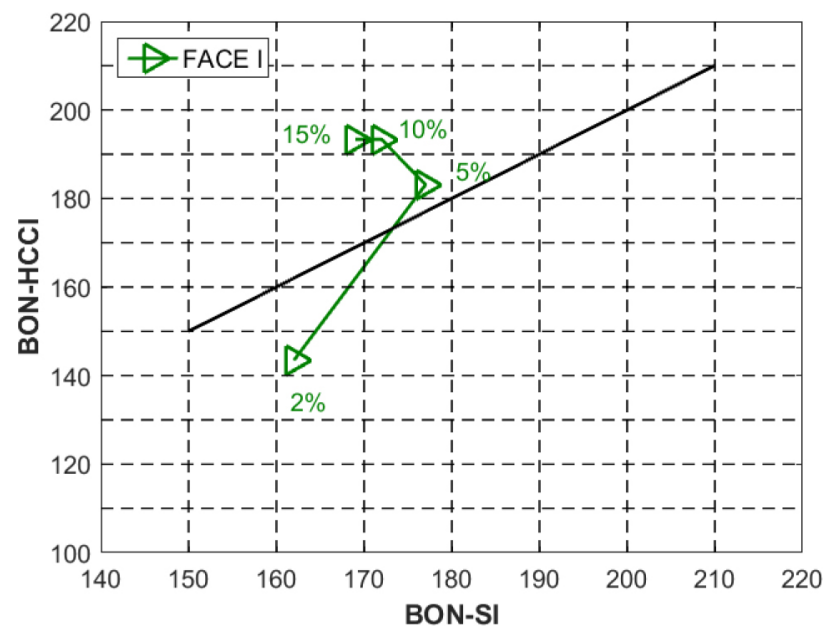

Figure 22. Blending octane numbers for FACE I in SI and HCCI modes at 600 $\mathrm{rpm}, \mathrm{T}_{\text {in }}=52^{\circ} \mathrm{C}$

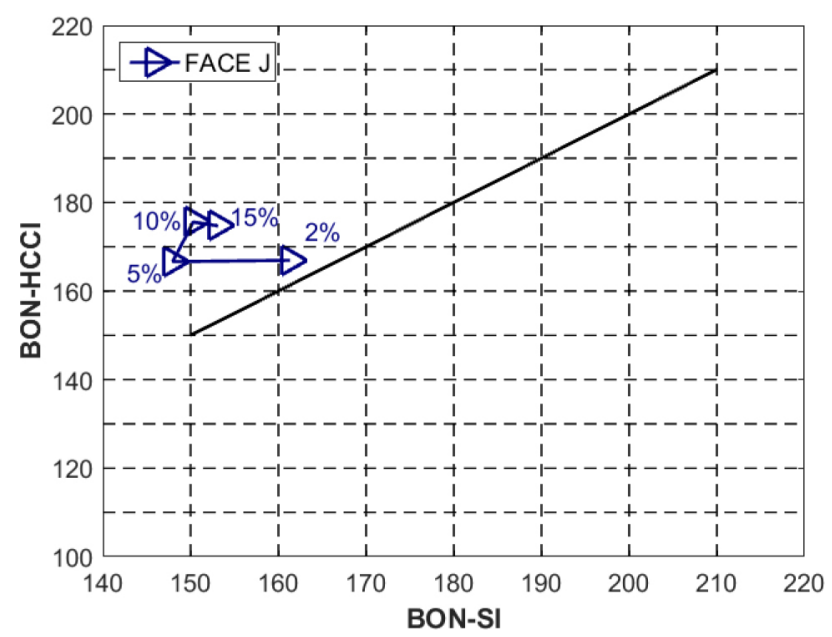

Figure 23. Blending octane numbers for FACE J in SI and HCCI modes at 600 $\mathrm{rpm}, \mathrm{T}_{\mathrm{in}}=52^{\circ} \mathrm{C}$

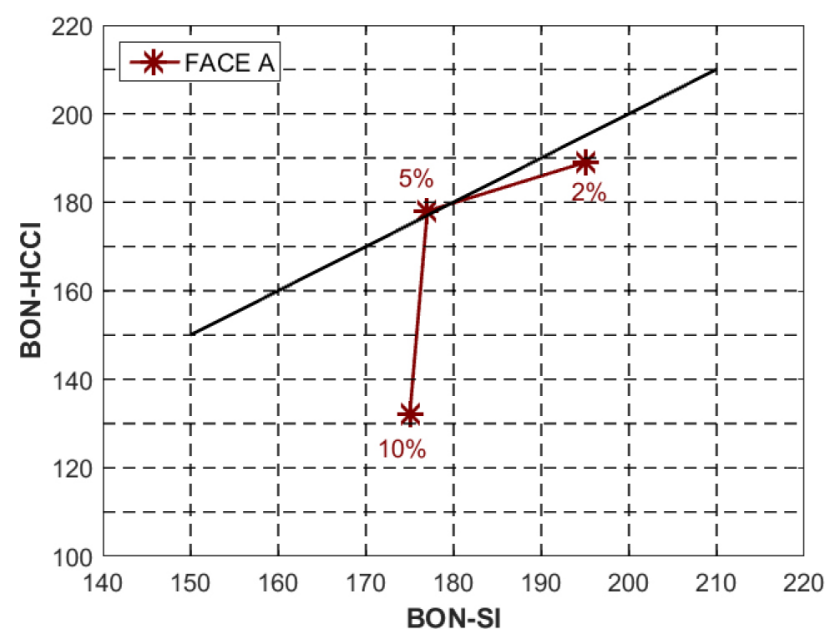

Figure 24. Blending octane numbers for FACE A in SI and HCCI modes at $600 \mathrm{rpm}, \mathrm{T}_{\text {in }}=52^{\circ} \mathrm{C}$

\section{$B D C N-I Q T$ vs BON-SI}

$\underline{\text { Figures } 25}, \underline{26}$ and 27 presents the Blending Derived Cetane Number with BON-SI for FACE I, FACE J and FACE A respectively. It is observed that as the ethanol concentration is increased from $5 \%$ to $15 \%$, an increased in BDCN-IQT is observed for all FACE fuels. FACE I and FACE A showed a decrease in BON-SI with the increase in BDCN-IQT. This could be due to both having the same aromatic concentration. It was observed for SI case that FACE I and FACE A behaved similarly. This suggests that FACE I and FACE A could be behaving similar in both rich and stoichiometric combustion. The change in the BDCN-IQT as ethanol concentration was increased was quite small for both FACE I and FACE A suggesting that addition of ethanol had a little effect on the rich auto-ignition for the fuels having same aromatic concentration. The FACE J showed an opposite trend than FACE I and FACE A and that could be due to its high aromatic contents. The change in the BDCN-IQT for FACE J was quite large as ethanol concentration was increased. This reflects that in the presence of aromatics, ethanol has a strong influence on the rich autoignition.

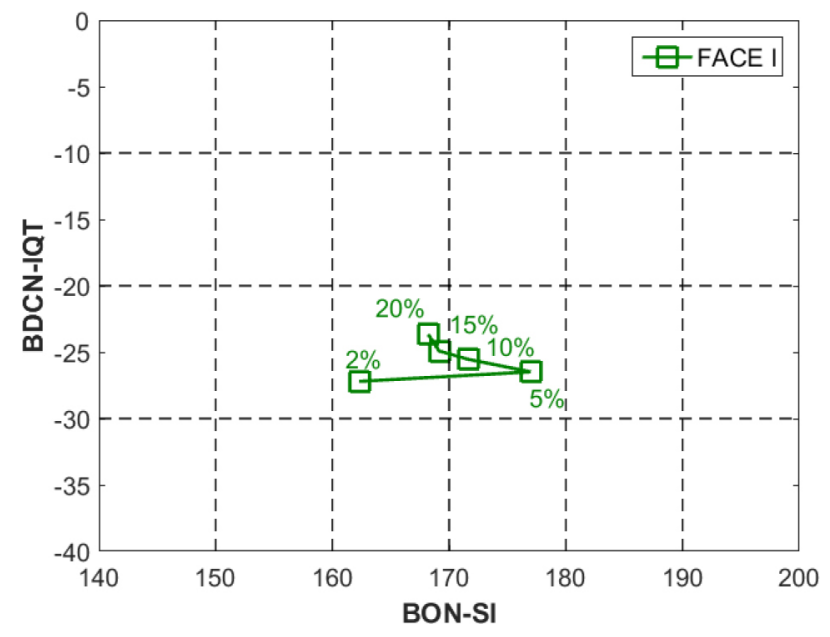

Figure 25. BDCN-IQT vs BON-SI for FACE I

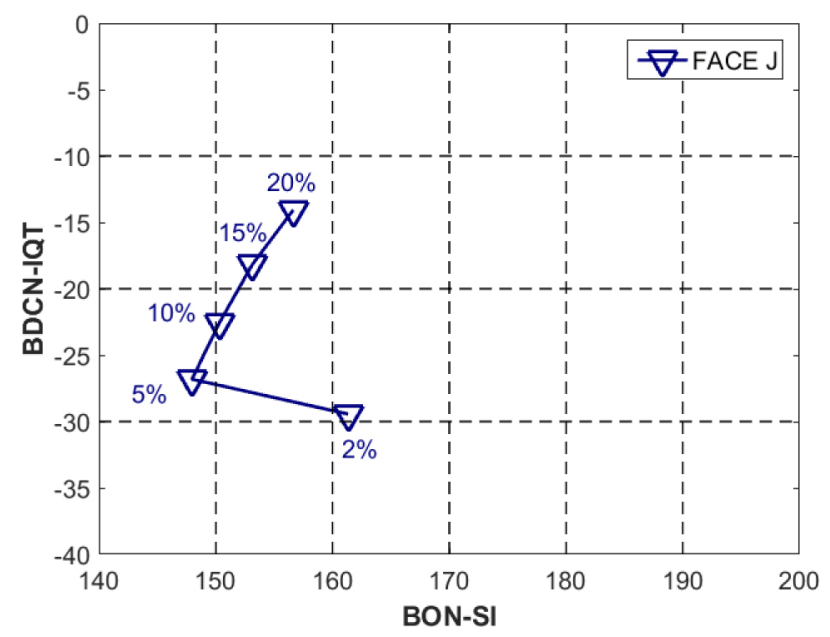

Figure 26. BDCN-IQT vs BON-SI for FACE J 


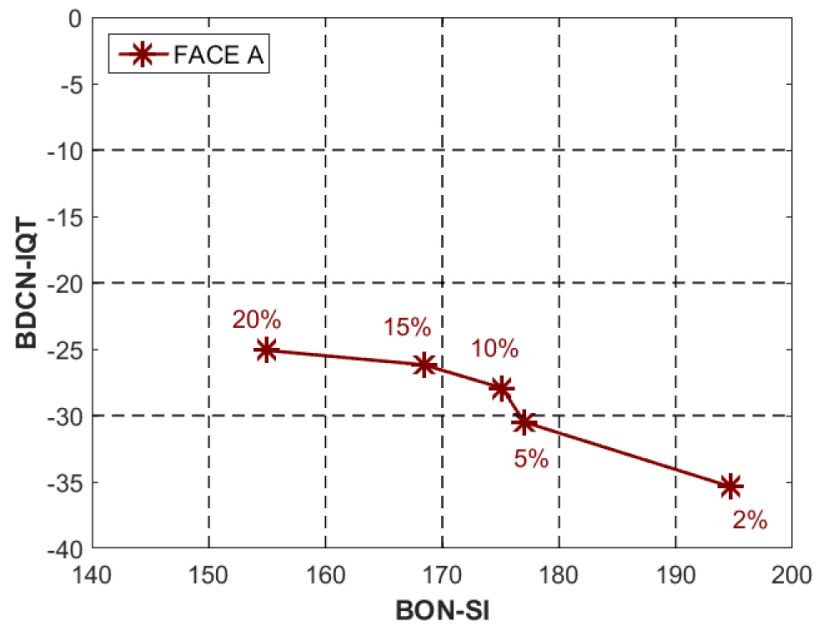

Figure 27. BDCN-IQT vs BON-SI for FACE A

\section{DISCUSSION}

The results obtained from SI, HCCI and IQT highlights that FACE fuels and PRFs behave differently in all three conditions: rich autoignition as in the IQT, very lean auto ignition (HCCI) and stoichiometric (SI knock). Ethanol was added to the base fuels and PRFs to improve its anti-knock quality. The anti-knock quality of ethanol is related to the molecular structure of the base fuel [45]. The auto-ignition behavior of gasoline aromatic component is significantly affected by the degree of alkyl substitution to the aromatic ring [45]. The knocking tendency of the fuel is also affected by the position of the methyl branches attached to the ring structure of the aromatics [ㄷ5]. FACE fuels studied here comprise mainly toluene, xylene isomers, and trimethylbenzene isomers.

The future development in SI engines will be focused mainly in improving the efficiency which is related to the anti-knock of the fuel [45]. Addition of ethanol in FACE fuels showed an increase in the RON and hence improvement in the anti-knock quality which highlights the potential use of low RON fuels with oxygenated additives. Previous studies have also highlighted the potential use of low RON fuel with the high octane booster $[\underline{10}, \underline{20}, \underline{21}]$. The CI engines for future are targeted to reduce soot and $\mathrm{NO}_{\mathrm{x}}$ without comprising the efficiency [45]. That could be achieved by Low Octane gasoline with RON between 70 and 85 [도]. The FACE gasolines tested are in the RON range of 70-83.5 and can be quite useful for future CI engines [45]. The addition of small quantities of ethanol to FACE I and FACE J can help to increase the octane number for efficiency purposes and at the same time emissions are reduced. The fuel aromatic and octane sensitivity are important in determining HCCI operating range [ㄴ6]. It has been found that aromatics with percentage greater than $35 \%$ compared to high olefins can help to increase the operating range for HCCI [46]. Among the FACE gasolines, FACE J with $35 \%$ aromatics can potentially be a viable fuel for $\mathrm{HCCI}$ in the future.
The blending octane numbers for all ethanol percentages were estimated using the base RON or HCCI at $0 \%$ ethanol. It was expected that the BON would decrease with the addition of ethanol but that was not observed for some cases. Appendix E shows the incremental blending octane number (IBON) estimated using the intermediate percentages of ethanol. For e.g. to estimate the BON at $10 \%$ ethanol, RON for $5 \%$ was used as a base RON rather than RON at $0 \%$ ethanol. For $20 \%$ BON, base RON of $10 \%$ was used. The results showed that IBON decreased with ethanol addition for all fuels tested. With $20 \%$ ethanol addition, the IBON nearly approached the RON of ethanol.

\section{CONCLUSIONS}

The non-linear octane boosting effect of ethanol was studied with auto ignition of stoichiometric (SI), rich (CI) and lean (HCCI) mixtures using different base fuels consisting of FACE gasolines and PRFs with octane number of 70 and 84 respectively. The following are the conclusions derived from all experiments:-

- The blending octane number for SI and HCCI and the blending derived cetane number for CI modes can be derived to explain the large suppression of auto-ignition caused by the addition of ethanol with base fuels.

- The blending octane number is positive and around 200 and the blending derived cetane number is negative and around -50 for small concentrations of ethanol. Both of them change with base fuel octane rating and ethanol concentration.

- The blending octane number for some base fuels decreases with ethanol addition, while for some fuels stays reasonably constant in the range 2 to $20 \%$ tested.

- The operating conditions such as speed and temperature had a strong influence on the results. The HCCI number was derived at four conditions; $600,900 \mathrm{rpm}$ and $52^{\circ} \mathrm{C}, 149^{\circ} \mathrm{C}$ in the inlet. This is not only the conditions for RON and MON in SI mode but also with only speed or inlet temperature changed. The effects of speed and inlet temperature were not additive.

- The addition of ethanol with base fuels having same aromatics contents i.e. FACE I and FACE A showed a similar non-linear effect. Different base octane number does not seem to have any influence on the behavior of blending octane number of ethanol for both FACE gasolines. This was true for both SI and CI mode.

- Base octane number for FACE gasolines with same aromatic content in HCCI mode had a strong influence on the four HCCI numbers. With FACE A and FACE I as a base fuel with octane number 70.3 and 83.5 respectively, the blending octane number of ethanol behaved differently.

- Among the FACE gasolines, base gasoline with higher aromatic contents when blended with ethanol results in lower blending octane number, which indicates that ethanol, is less effective at increasing octane number of fuels with high aromatic content. This was generally observed independent of combustion mode. The blending octane number of ethanol was lower in both SI and HCCI conditions with FACE J as base fuel that has higher aromatic contents. 
- With a base fuel having a fixed 84 octane number the blending octane number of ethanol changed with base fuel composition. With PRF84 as base fuel ethanol had a higher blending octane number than with FACE A as a base. The aromatic content of FACE A did not change the blending octane number of ethanol when tested in HCCI or CI modes.

- In general there was a correlation between SI, HCCI and CI combustion process but all the fuels did not respond in the same manner.

- The intermediate blending octane number, i.e. the incremental change for $0-2 \%, 2-5 \%, 5-10 \%, 10-15 \%$ and $15-20 \%$ has a much faster decay towards the octane number of ethanol than the blending octane number defined from $0 \%$ to a certain percentage. This indicates that ethanol effect is strongest at rather small percentages.

\section{REFERENCES}

1. Foong, T., Morganti, K., Brear, M., Silva, G. et al., "The octane numbers of ethanol blended with gasoline and its surrogates," Fuel, 115: 727-739, 2014, doi:10.1016/j.fuel.2013.07.105.

2. Partridge, R., Weissman, W., Ueda, T., Iwashita, Y. et al., "Onboard Gasoline Separation for Improved Vehicle Efficiency," SAE Int. J. Fuels Lubr. 7(2):366-378, 2014, doi:10.4271/2014-01-1200.

3. Sarathy, S., Oßwald, P., Hansen, N., and Kohse-Höinghaus, K.," Alcohol combustion chemistry," Progress in Energy and Combustion Science, 44:40-102, 2014, doi:10.1016/j.pecs.2014.04.003.

4. Larsen, U., Johansen, T., and Schramm, J., "Ethanol as a fuel for road transportation," Main Report. IEA-AMF report, 100: , May 2009.

5. Chow, E., Heywood, J., and Speth, R., "Benefits of a Higher Octane Standard Gasoline for the U.S. Light-Duty Vehicle Fleet," SAE Technical Paper 2014-01-1961, 2014, doi:10.4271/2014-01-1961.

6. Lee, S., Speight, J., and Loyalka, S., " Handbook of alternative fuel technologies, Second Edition," Ch: 1(16) and 12 (397), eBook ISBN : 978-1-4665-9457-9

7. Bhatia, S., "Advanced Renewable Energy Systems,(Part 1 and 2)," Ch: 16 (403), eBook ISBN: 978-1-78242-273-0.

8. Stein, R., House, C., and Leone, T., "Optimal Use of E85 in a Turbocharged Direct Injection Engine," SAE Int. J. Fuels Lubr. 2(1):670682, 2009, doi:10.4271/2009-01-1490.

9. Stein, R., Anderson, J., and Wallington, T., "An Overview of the Effects of Ethanol-Gasoline Blends on SI Engine Performance, Fuel Efficiency, and Emissions," SAE Int. J. Engines 6(1):470-487, 2013, doi:10.4271/2013-01-1635.

10. Viollet, Y., Abdullah, M., Alhajhouje, A., and Chang, J., "Characterization of High Efficiency Octane-On-Demand Fuels Requirement in a Modern Spark Ignition Engine with Dual Injection System," SAE Technical Paper 2015-01-1265, 2015, doi:10.4271/201501-1265.

11. Chupka, G., Christensen, E., Fouts, L., Alleman, T. et al., "Heat of Vaporization Measurements for Ethanol Blends Up To 50 Volume Percent in Several Hydrocarbon Blendstocks and Implications for Knock in SI Engines," SAE Int. J. Fuels Lubr. 8(2):251-263, 2015, doi:10.4271/2015-01-0763.

12. Rankovic, N., Bourhis, G., Loos, M., and Dauphin, R., "Understanding octane number evolution for enabling alternative low RON refinery streams and octane boosters as transportation fuels,"Fuel, 150: 41-47, 2015, doi:10.1016/j.fuel.2015.02.005.

13. Anderson, J., Leone, T., Shelby, M., Wallington, T. et al., "Octane Numbers of Ethanol-Gasoline Blends: Measurements and Novel Estimation Method from Molar Composition," SAE Technical Paper 2012-01-1274, 2012, doi:10.4271/2012-01-1274.

14. Ramadan, A., Sarathy, S., Khurshid, M., and Badra, J., "A blending rule for octane numbers of PRFs and TPRFs with ethanol," Fuel, 180: 175186, 2016, doi:10.1016/j.fuel.2016.04.032.

15. Wang, Z., Liu, H., Long, Y., Wang, X. et al., "Comparative study on alcohols-gasoline and gasoline-alcohols dual-fuel spark ignition (DFSI) combustion for high load extension and high fuel efficiency," Energy, 82: 395-405, 2015, doi:10.1016/j.energy.2015.01.049.
16. Liu, H., Wang, Z., and Wang, J., "Methanol-gasoline DFSI (dualfuel spark ignition) combustion with dual-injection for engine knock suppression," Energy, 73: 686-693, 2014, doi:10.1016/j. energy.2014.06.072.

17. Daniel, R., Wang, C., Xu, H., Tian, G. et al., "Dual-Injection as a Knock Mitigation Strategy Using Pure Ethanol and Methanol," SAE Int. J. Fuels Lubr. 5(2):772-784, 2012, doi:10.4271/2012-01-1152.

18. Chang, J., Viollet, Y., Alzubail, A., Abdul-Manan, A. et al., "Octane-onDemand as an Enabler for Highly Efficient Spark Ignition Engines and Greenhouse Gas Emissions Improvement," SAE Technical Paper 201501-1264, 2015, doi:10.4271/2015-01-1264.

19. Bourhis, G., Solari, J., Morel, V., and Dauphin, R., "Using Ethanol's Double Octane Boosting Effect with Low RON Naphtha-Based Fuel for an Octane on Demand SI Engine," SAE Int. J. Engines 9(3):2016, doi: $10.4271 / 2016-01-0666$.

20. Morganti, K., Abdullah, M., Alzubail, A., Viollet, Y. et al., "Improving the Efficiency of Conventional Spark-Ignition Engines Using Octaneon-Demand Combustion. Part I: Engine Studies," SAE Technical Paper 2016-01-0679, 2016, doi:10.4271/2016-01-0679.

21. Morganti, K., Alzubail, A., Abdullah, M., Viollet, Y. et al., "Improving the Efficiency of Conventional Spark-Ignition Engines Using Octane-on-Demand Combustion - Part II: Vehicle Studies and Life Cycle Assessment," SAE Technical Paper 2016-01-0683, 2016, doi:10.4271/2016-01-0683.

22. Ojapah, M., Zhao, H., and Zhang, Y., "Effects of ethanol on combustion and emissions of a gasoline engine operating with different combustion modes," International J of Engine Research, March 14, 2016 , doi: $10.1177 / 1468087416634517$.

23. Ng, H., and Charalamdides, A., " Charalambides Alexandros G. (2013). Homogenous Charge Compression Ignition (HCCI) Engines, Advances in Internal Combustion Engines and Fuel Technologies, InTech Open Access Publisher, 2013, doi: 10.5772/55807.

24. Aroonsrisopon, T., Foster, D., Morikawa, T., and Iida, M., "Comparison of HCCI Operating Ranges for Combinations of Intake Temperature, Engine Speed and Fuel Composition," SAE Technical Paper 2002-011924, 2002, doi:10.4271/2002-01-1924.

25. Kalghatgi, G., "Fuel Anti-Knock Quality - Part I. Engine Studies," SAE Technical Paper 2001-01-3584, 2001, doi:10.4271/2001-01-3584.

26. Truedsson, I., Cannella, W., Johansson, B., and Tuner, M., "Development of New Test Method for Evaluating HCCI Fuel Performance," SAE Technical Paper 2014-01-2667, 2014, doi:10.4271/2014-01-2667.

27. Dryer, F., "Chemical kinetic and combustion characteristics of transportation fuels," Proceedings of the Combustion Institute, 35(1): 117-144, 2014, doi:10.1016/j.proci.2014.09.008.

28. Olsson, J., Tunestål, P., Haraldsson, G., and Johansson, B., "A Turbo Charged Dual Fuel HCCI Engine," SAE Technical Paper 2001-01-1896, 2001, doi:10.4271/2001-01-1896.

29. Aldawood, A., Mosbach, S., Kraft, M., and Amer, A., "Dual-Fuel Effects on HCCI Operating Range: Experiments with Primary Reference Fuels," SAE Technical Paper 2013-01-1673, 2013, doi:10.4271/2013-01-1673.

30. Aldawood, A., Mosbach, S., and Kraft, M., "HCCI Combustion Control Using Dual-Fuel Approach: Experimental and Modeling Investigations," SAE Technical Paper 2012-01-1117, 2012, doi:10.4271/2012-01-1117.

31. Dec, J., "Advanced compression-ignition engines-understanding the in-cylinder processes," Proceedings of the Combustion Institute, 32: 2727-2742, 2009, doi:10.1016/j.proci.2008.08.008.

32. Yahuza, I., and Dandakouta, H., "A Performance Review of EthanolDiesel Blended Fuel Samples in Compression-Ignition Engine," Journal of Chemical Engineering \& Process Technology, 6: 1, 2015, doi:10.4172/2157-7048.1000256.

33. Cannella, W., Foster, F., Gunter, G., and Leppard, W., "FACE Gasolines and Blends with Ethanol: Detailed Characterization of Physical and Chemical Properties," CRC Report No AVFL-24, July, 2014.

34. Bhavani Shankar, V., Sajid, M., Al-Qurashi, K., Atef, N. et al., "Primary Reference Fuels (PRFs) as Surrogates for Low Sensitivity Gasoline Fuels," SAE Technical Paper 2016-01-0748, 2016, doi:10.4271/2016-01$\underline{0748}$.

35. Sarathy, S., Kukkadapu, G., Mehl, M., Wang, W. et al, "Ignition of alkane-rich FACE gasoline fuels and their surrogate mixtures," Proceedings of the Combustion Institute, 35: 249-257, 2015, doi:10.1016/j.proci.2014.05.122.

36. Ahmed, A., Goteng, G., Shankar, V., Al-Qurashi, K. et al, "A computational methodology for formulating gasoline surrogate fuels with accurate physical and chemical kinetic properties," Fuel, 143: 290300, 2015, doi:10.1016/j.fuel.2014.11.022. 
37. Chen, C., Wang, Z., Dagaut, P., and Sarathy, S., "Jet-stirred reactor oxidation of alkane-rich FACE gasoline fuels.," accepted to Proc. Combust. Inst., : December, 2015.

38. Sarathy, S., Kukkadapu, G., Mehl, M., Javed, T. et al "Compositional effects on the ignition of FACE gasoline fuels.," Accepted to Combustion and Flame, 169, April 171-193, 2016.

39. ASTM D6890-16, " Standard Test Method for Determination of Ignition Delay and Derived Cetane Number (DCN) of Diesel Fuel Oils by Combustion in a Constant Volume Chamber," ASTM International, West Conshohocken, PA, 2016, doi: 10.1520/D6890-16.

40. Yang, S., Naser, N., Chung, S., and Cha, J., "Effect of Temperature, Pressure and Equivalence Ratio on Ignition Delay in Ignition Quality Tester (IQT): Diesel, n-Heptane, and iso-Octane Fuels under Low Temperature Conditions," SAE Int. J. Fuels Lubr. 8(3):537-548, 2015, doi:10.4271/2015-01-9074.

41. ASTM D2699-13b, " Standard Test Method for Research Octane Number of Spark-Ignition Engine Fuel," ASTM International, West Conshohocken, PA, 2013, doi: 10.1520/D2699.

42. ASTM D2700-14, "Standard Test Method for Motor Octane Number of Spark-Ignition Engine Fuel," ASTM International, West Conshohocken, PA, 2016, doi: 10.1520/D2700-16.

43. Silva, R., Cataluna, R., Menezes, E., Samios, D. et al "Effect of additives on the antiknock properties and Reid vapor pressure of gasoline," Fuel, 84: 951-959, 2005, doi:10.1016/j.fuel.2005.01.008.

44. Foong, T., Morganti, K., Brear, M., da Silva, G. et al., "The Effect of Charge Cooling on the RON of Ethanol/Gasoline Blends," SAE Int. J. Fuels Lubr.6(1):34-43, 2013, doi:10.4271/2013-01-0886.

45. Kalghatgi, G., "The outlook for fuels for internal combustion engines," International J of Engine Research, March 14, 2014, doi: $\underline{10.1177 / 1468087414526189 .}$.

46. Lacey, J., Filipi, Z., Sathasivam, S., Cannella, W. et al., "HCCI Operability Limits: The Impact of Refinery Stream Gasoline Property Variation,"J. Eng. Gas Turbines Power 135(8), 081505 ,Jul 05, 2013, doi: 10.1115/1/4024260.

\section{CONTACT}

Prof. Bengt Johansson

Bengt.Johansson@

\section{ACKNOWLEDGEMENTS}

The authors would like to thank Clean Combustion Research Lab for providing the engine experiment facilities. The published paper was supported by competitive research funding from King Abdullah University of Science and Technology (KAUST) and funds from Saudi Aramco under the FUELCOM program.

\section{DEFINITIONS/ABBREVIATIONS}

BDCN - Blending Derived Cetane Number

bTDC - Before Top Dead Center

BON - Blending Octane Number

CAD - Crank Angle Degree

CA50 - Crank Angle for 50\% heat release

CFR - Cooperative Fuel Research

CI - Compression Ignition

DCN - Derived Cetane Number

FACE - Fuels for Advanced Combustion Engines

HCCI - Homogeneous Charge Compression Ignition

IQT - Ignition Quality Tester

IBON - Incremental Blending Octane Number

PRFs - Primary Reference Fuels

MON - Motor Octane Number
RON - Research Octane Number

ST - Spark Timing

SI - Spark Ignition

TDC - Top Dead Center 


\section{APPENDIX}

\section{Appendix A}

Table A1. FACE fuel blends (Blend description: First letter: Ethanol, Second letter: FACE fuel type, Third digit: Ethanol percentage in the blend)

\begin{tabular}{|l|l|l|l|l|}
\hline $\begin{array}{l}\text { Fuel } \\
\text { blends }\end{array}$ & $\begin{array}{l}\text { FACE I } \\
(\%)\end{array}$ & $\begin{array}{l}\text { FACE J } \\
(\%)\end{array}$ & $\begin{array}{l}\text { FACE A } \\
(\%)\end{array}$ & $\begin{array}{l}\text { Ethanol } \\
(\%)\end{array}$ \\
\hline EI0 & 100 & - & - & 0 \\
\hline EI2 & 98 & - & - & 2 \\
\hline EI5 & 95 & - & - & 5 \\
\hline EI10 & 90 & - & - & 10 \\
\hline EI15 & 85 & - & - & 15 \\
\hline EI20 & 80 & - & - & 20 \\
\hline EJ0 & - & 100 & - & 0 \\
\hline EJ2 & - & 98 & - & 2 \\
\hline EJ5 & - & 95 & - & 5 \\
\hline EJ10 & - & 90 & - & 10 \\
\hline EJ15 & - & 85 & - & 15 \\
\hline EJ20 & - & 80 & - & 20 \\
\hline EA0 & - & - & 100 & 0 \\
\hline EA2 & - & - & 98 & 2 \\
\hline EA5 & - & - & 95 & 5 \\
\hline EA10 & - & - & 90 & 10 \\
\hline EA15 & - & - & 85 & 15 \\
\hline EA20 & - & - & 80 & 20 \\
\hline
\end{tabular}

Table A2. Primary Reference fuel (PRF) blends (Blend description: PRF: Combination of Iso-Octane-n-heptane, digit after PRF :percentage of Iso-Octane, E: Ethanol, last digit: Ethanol percentage in the blend)

\begin{tabular}{|l|l|l|l|}
\hline Fuel blends & PRF70 & PRF84 & Ethanol (\%) \\
\hline PRF70-E0 & 100 & - & 0 \\
\hline PRF70-E2 & 98 & - & 2 \\
\hline PRF70-E5 & 95 & - & 5 \\
\hline PRF70-E10 & 90 & - & 10 \\
\hline PRF70-E15 & 85 & - & 15 \\
\hline PRF70-E20 & 80 & - & 20 \\
\hline PRF84-E0 & - & 100 & 0 \\
\hline PRF84-E2 & - & 98 & 2 \\
\hline PRF84-E5 & - & 95 & 5 \\
\hline PRF84-E10 & - & 90 & 10 \\
\hline PRF84-E15 & - & 85 & 15 \\
\hline PRF84-E20 & - & 80 & 20 \\
\hline
\end{tabular}


Table A3. Constant values for best fit line belonging to Reference curve of SI condition

\begin{tabular}{|l|l|l|l|}
\hline Operating Condition & $a$ & $b$ & $c$ \\
\hline $\begin{array}{l}\text { RON-(600rpm, } \mathrm{T}_{\mathrm{in}}= \\
\left.52^{\circ} \mathrm{C}\right)\end{array}$ & -8.2937 & 122.68 & -353.86 \\
\hline
\end{tabular}

Table A4. Constant values for best fit lines belonging to Reference curves of four HCCI conditions

\begin{tabular}{|l|c|c|c|}
\hline Operating conditions & \multicolumn{1}{|c|}{$p$} & $q$ & $r$ \\
\hline HCCI-1(RON) & -2.1832 & 62.031 & -349.16 \\
\hline HCCI-2 & -0.8739 & 26.224 & -102.04 \\
\hline HCCI-3 & -0.9988 & 33.876 & -191.74 \\
\hline HCCI-4(MON) & -0.2641 & 13.232 & -42.738 \\
\hline
\end{tabular}

\section{Appendix B}

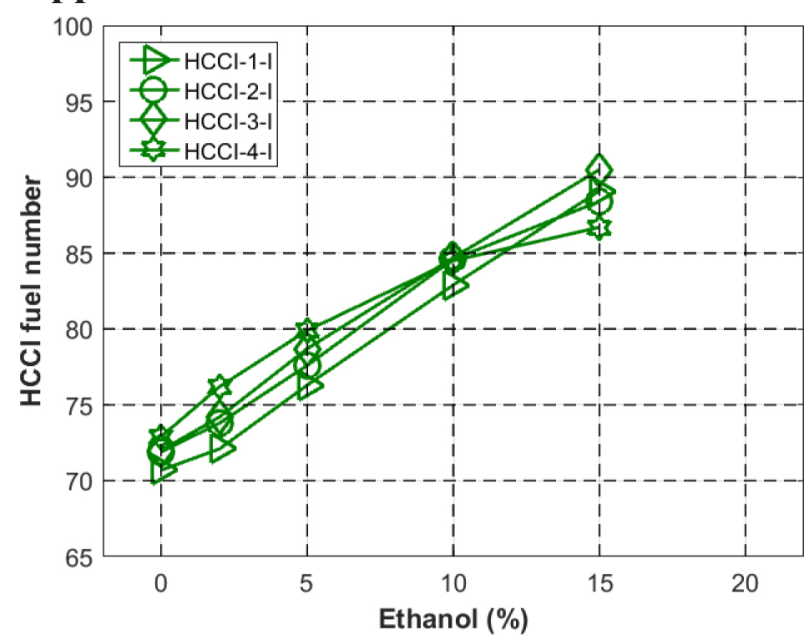

Figure A1. HCCI fuel number for FACE I, $\lambda=3$

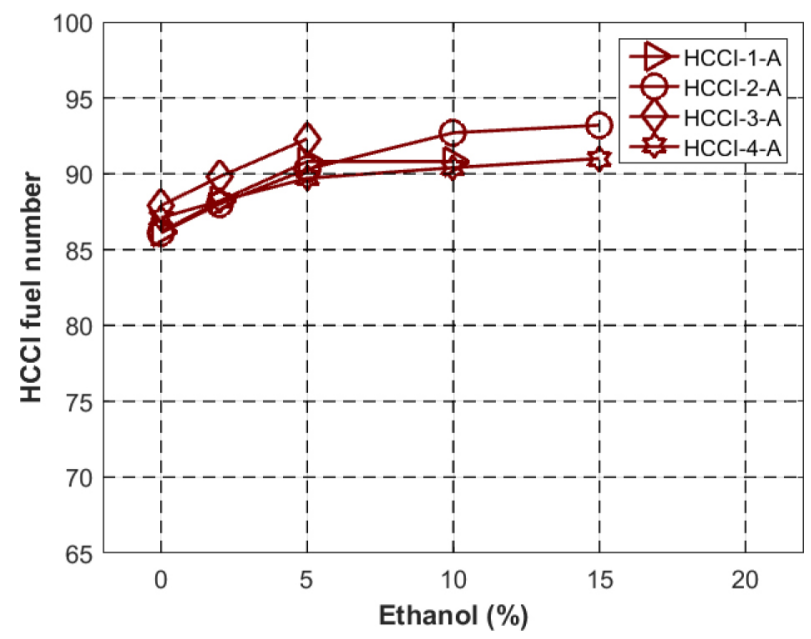

Figure A2. HCCI fuel number for FACE A, $\lambda=3$ 


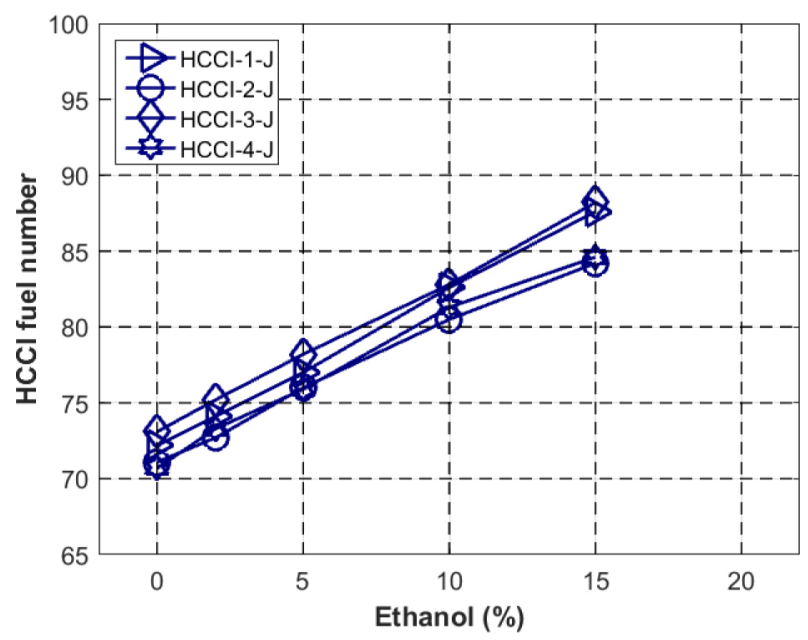

Figure A3. HCCI fuel number for FACE $J, \lambda=3$

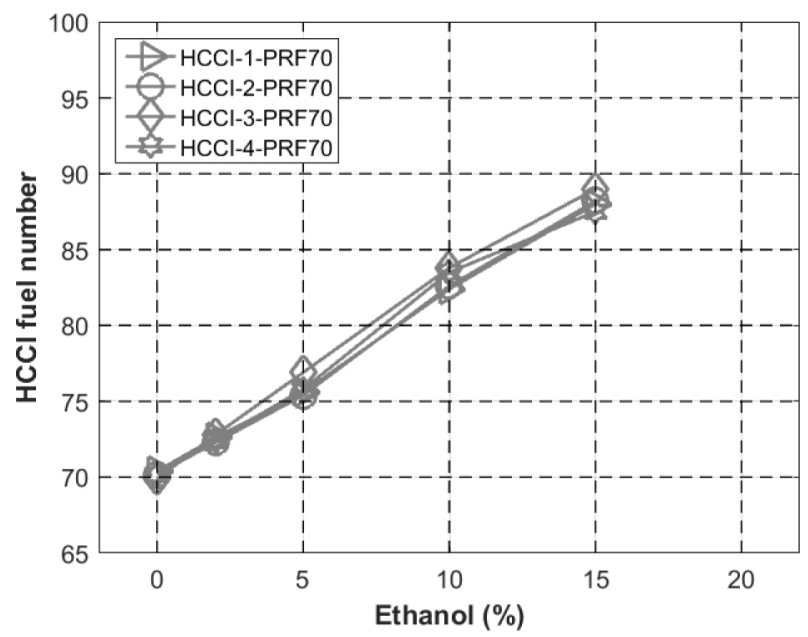

Figure A4. HCCI fuel number for PRF70, $\lambda=$

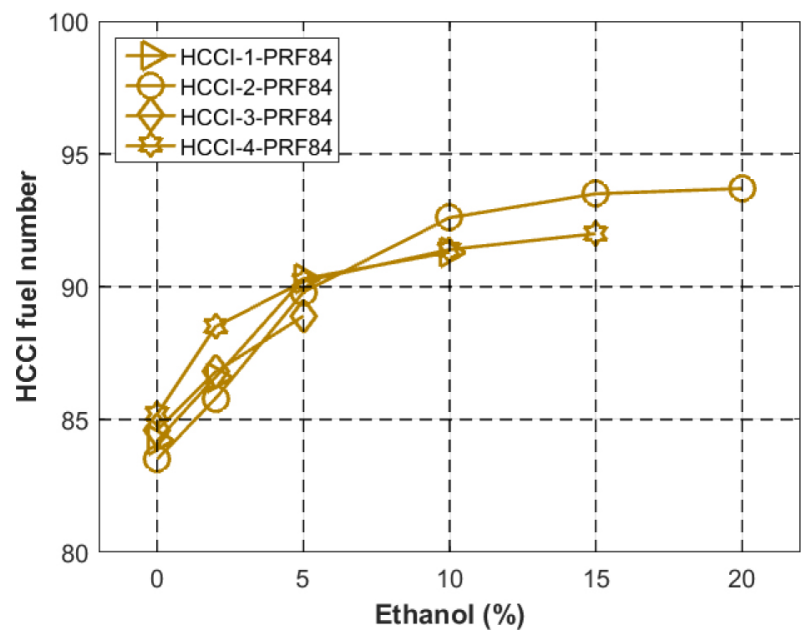

Figure A5. HCCI fuel number for PRF84, $\lambda=3$ 


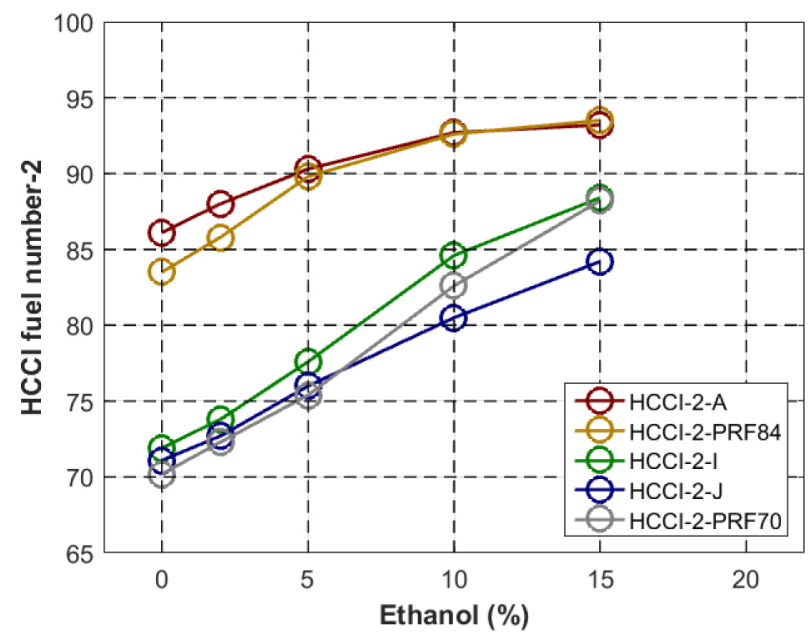

Figure A6. HCCI fuel number for $600 \mathrm{rpm}, \mathrm{T}_{\text {in }}=149^{\circ} \mathrm{C}$ and $\lambda=3$

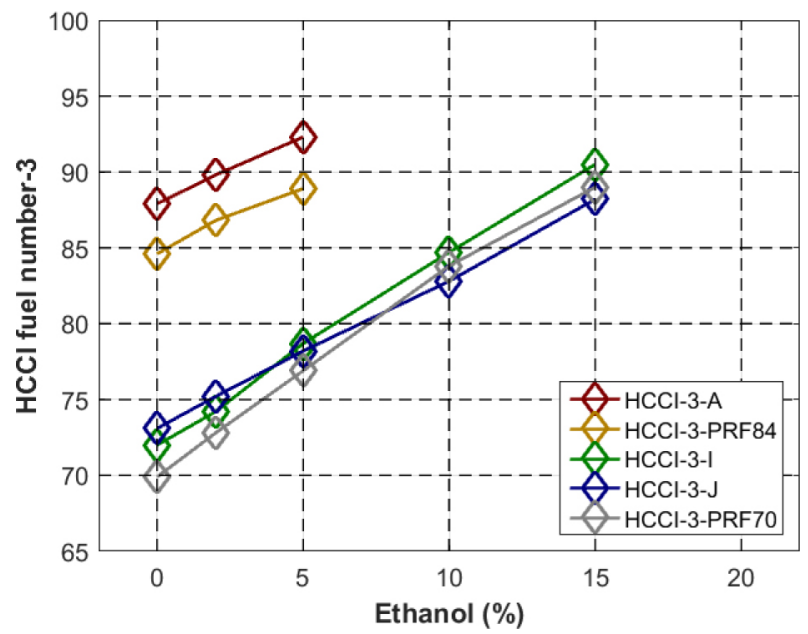

Figure A7. HCCI fuel number for $900 \mathrm{rpm}, \mathrm{T}_{\mathrm{in}}=52^{\circ} \mathrm{C}$ and $\lambda=3$

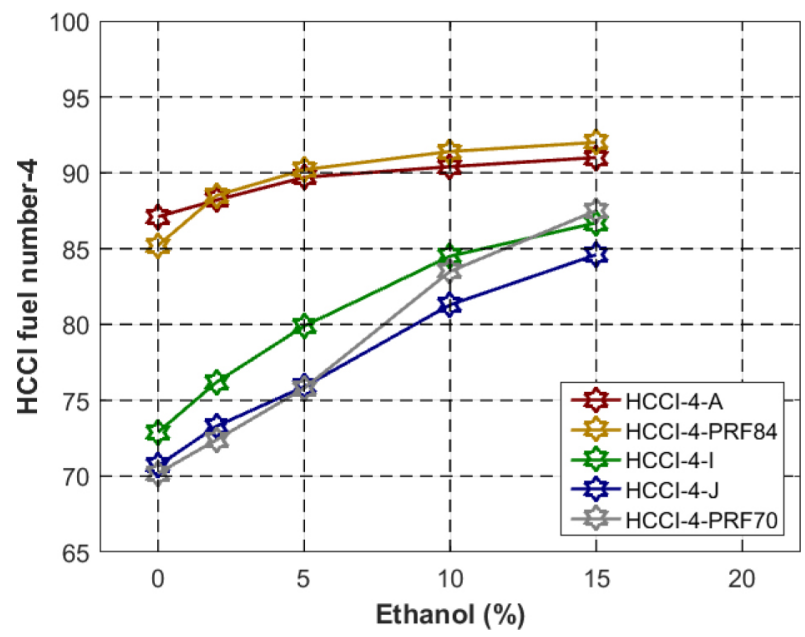

Figure A8. HCCI fuel number for $900 \mathrm{rpm}, \mathrm{T}_{\mathrm{in}}=149^{\circ} \mathrm{C}$ and $\lambda=3$ 


\section{Appendix C (Spark Ignition-Uncertainty analysis)}

The blending octane numbers were estimated from equation 3 for the spark ignition experiments. It was found that small changes in the RON will bring large effect on the BON values. Therefore it was decided to perform uncertainty analysis. The line of best fit obtained from $\underline{\text { Figure } 3}$ was used to estimate the RON and BON as explained in the main text. An error was calculated for each of the data points in Figure 3 . For e.g. compression ratio of 5.51 was obtained for RON 70. The line of best fit was used to estimate the RON at compression ratio of 5.51 and was found to be 70.309 giving an error of 0.309. In a similar manner an error for each of the data points were obtained. An average value of 0.329 for the error was obtained from all the data points. This average error value was further used to estimate the uncertainty in the BON. Below are the figures with the uncertainty bars.

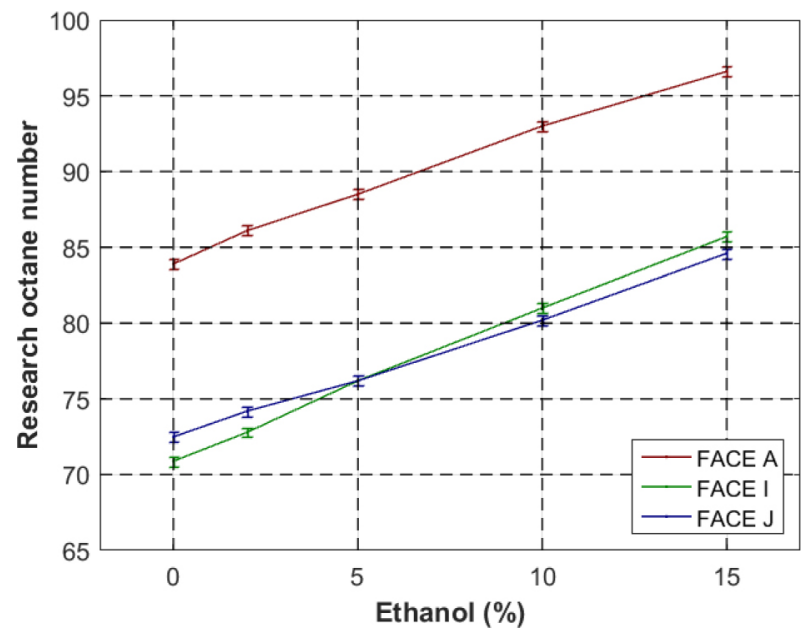

Figure A9. Uncertainity for RON of FACE I, J and A with ethanol concentration in SI mode, $600 \mathrm{rpm}, \mathrm{T}_{\text {in }}=52^{\circ} \mathrm{C}, \mathrm{ST}=-13 \mathrm{CAD}, \lambda=1$

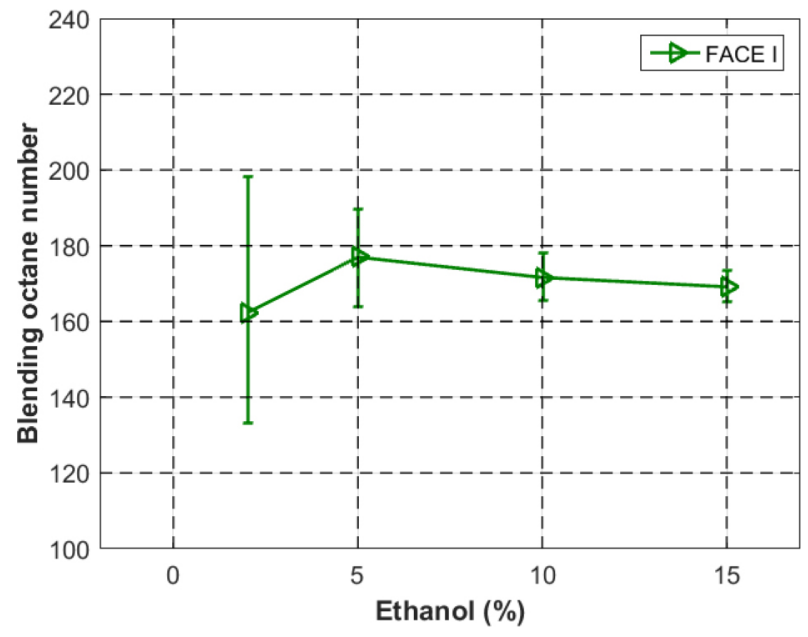

Figure A10. Uncertainty for Blending octane number for FACE I with ethanol concentration in SI mode, $600 \mathrm{rpm}, \mathrm{T}_{\text {in }}=52^{\circ} \mathrm{C}, \mathrm{ST}=-13 \mathrm{CAD}, \lambda=1$ 


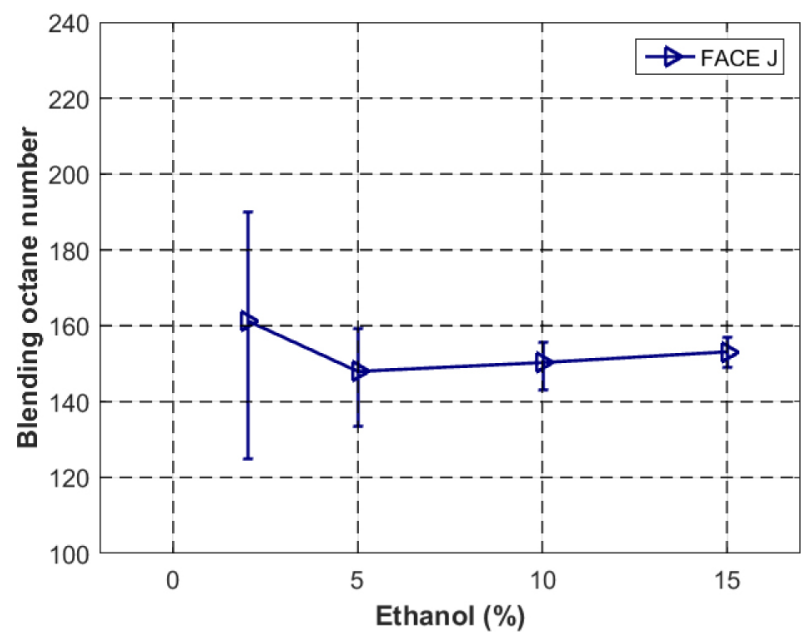

Figure A11. Uncertainty for Blending octane number for FACE J with ethanol concentration in $\mathrm{SI}$ mode, $600 \mathrm{rpm}, \mathrm{T}_{\mathrm{in}}=52^{\circ} \mathrm{C}, \mathrm{ST}=-13 \mathrm{CAD}, \lambda=1$

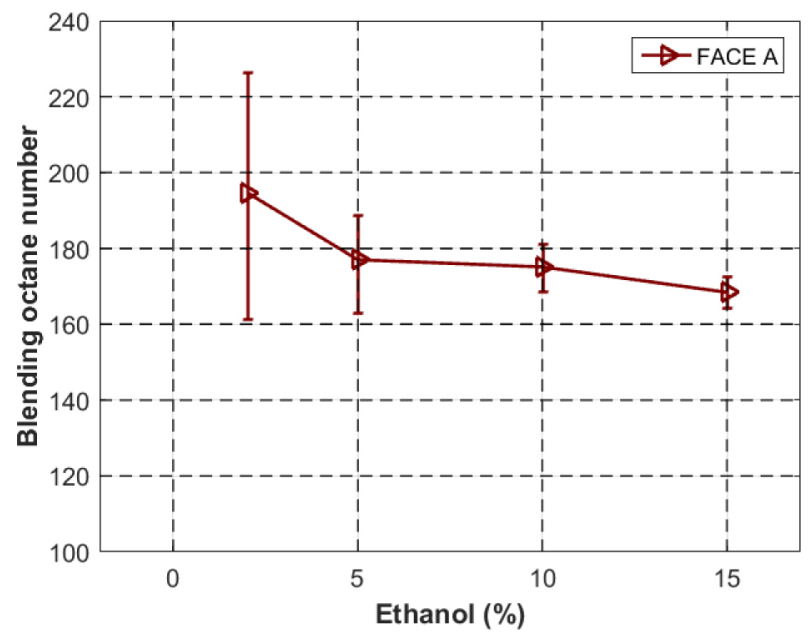

Figure A12. Uncertainty for Blending octane number for FACE A with ethanol concentration in SI mode, $600 \mathrm{rpm}, \mathrm{T}_{\text {in }}=52^{\circ} \mathrm{C}, \mathrm{ST}=-13 \mathrm{CAD}, \lambda=1$ 


\section{Appendix D (Homogeneous Charge Compression Ignition) (HCCI-1) - Uncertainty analysis}

It was identified that small changes in HCCI numbers will generate a large effect on the BON. Therefore uncertainty analysis was performed using the procedure explained in Appendix C. Figure 5 was used to estimate an error. Four different average errors were found for four HCCI numbers. The minimum average error was 0.152 corresponding to HCCI - 3 and the maximum average error was 0.281 corresponding to HCCI-1. It was decided to perform uncertainty analysis on HCCI-1 since it was a worst case scenario. Below are the figures corresponding to HCCI-1 number and the blending octane number for FACE I, FACE J, PRF 70, PRF 84 and FACE A.

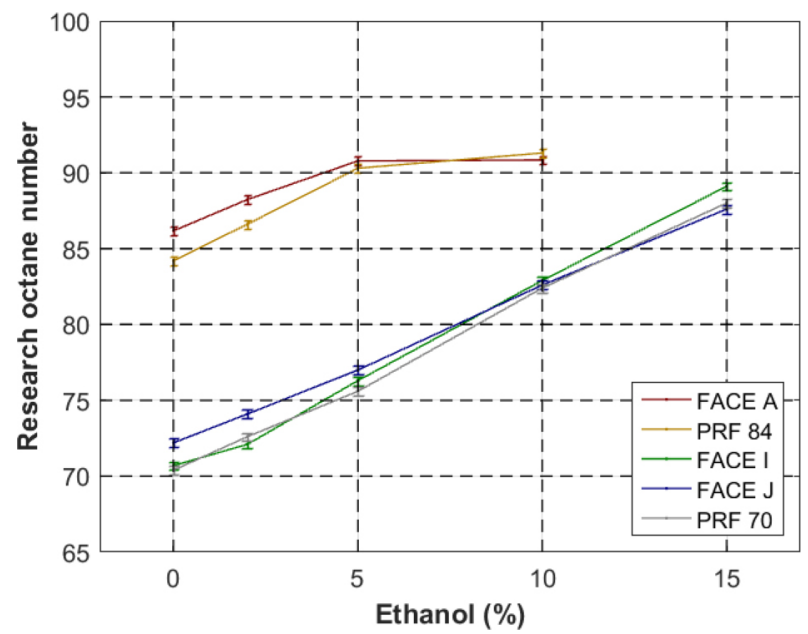

Figure A13. Uncertainity in HCCI fuel number for FACE fuels, PRFs at $600 \mathrm{rpm}, \mathrm{T}_{\text {in }}=52^{\circ} \mathrm{C}$ and $\lambda=3$

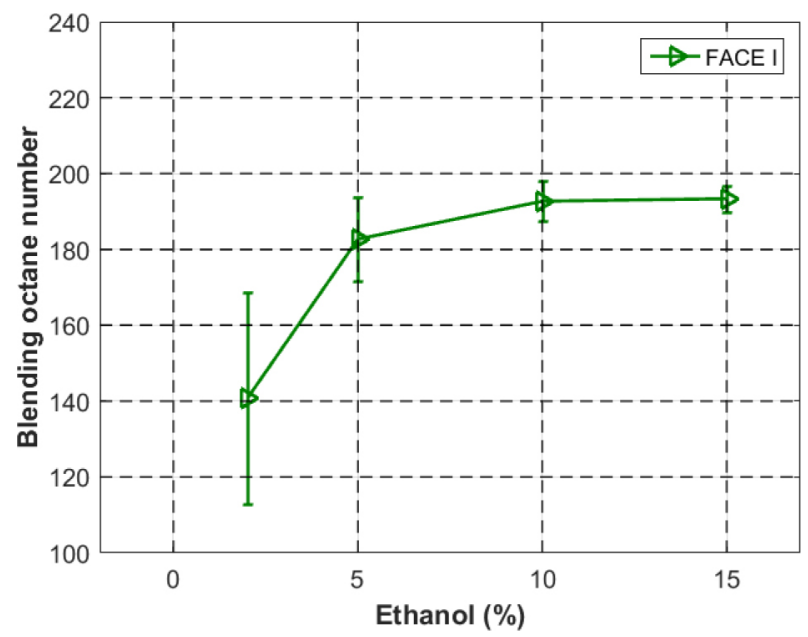

Figure A14. Uncertainty in Blending octane number for FACE I at $600 \mathrm{rpm}, \mathrm{T}_{\text {in }}=52^{\circ} \mathrm{C}$ and $\lambda=3$

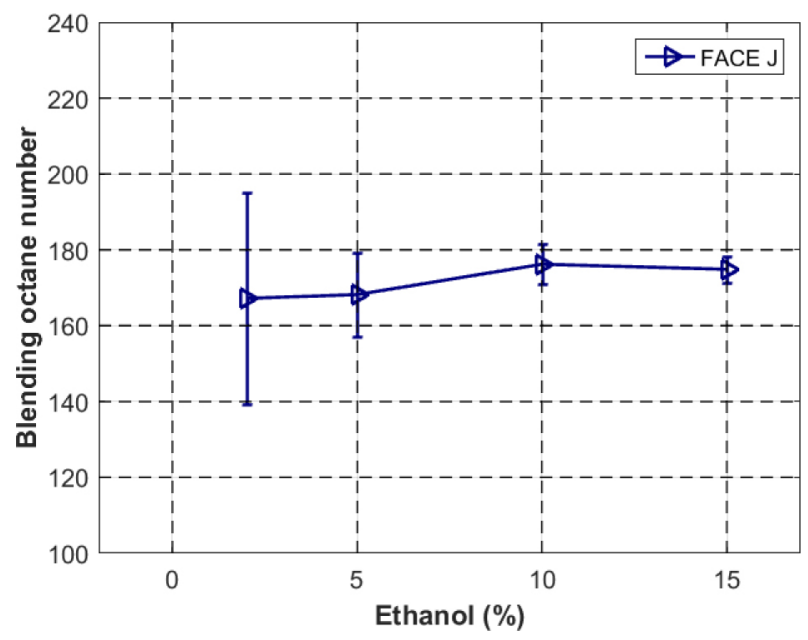

Figure A15. Uncertainty in Blending octane number for FACE J at $600 \mathrm{rpm}, \mathrm{T}_{\text {in }}=52^{\circ} \mathrm{C}$ and $\lambda=3$ 


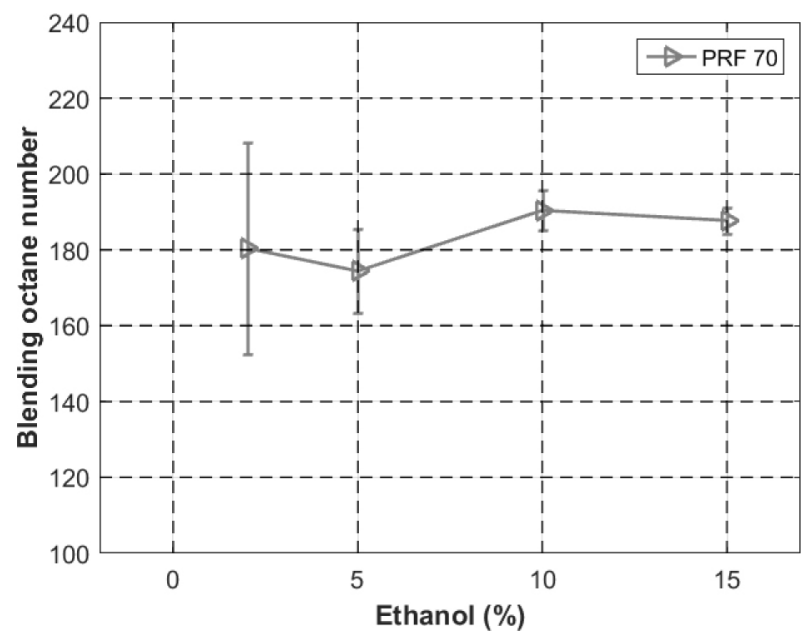

Figure A16. Uncertainty in Blending octane number for PRF70 at $600 \mathrm{rpm}, \mathrm{T}_{\text {in }}=52^{\circ} \mathrm{C}$ and $\lambda=3$

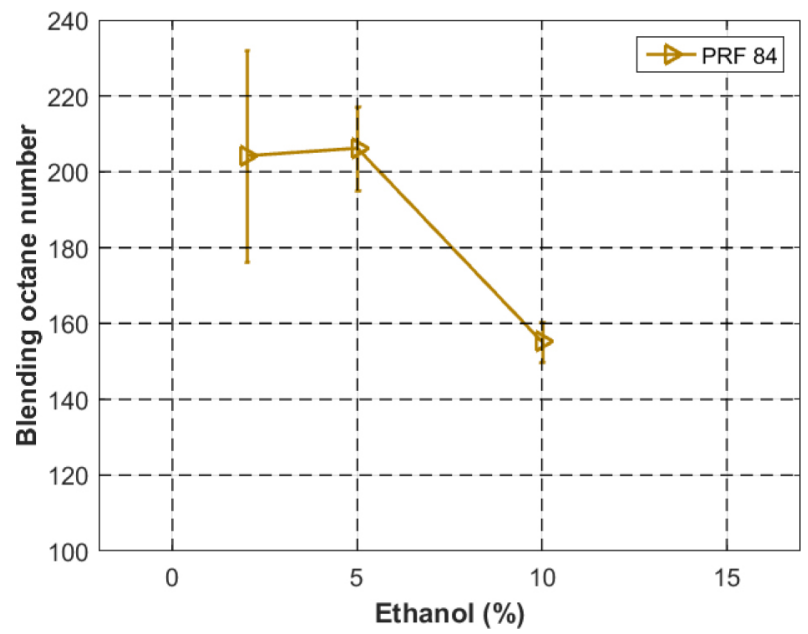

Figure A17. Uncertainty in Blending octane number for PRF84 at $600 \mathrm{rpm}, \mathrm{T}_{\text {in }}=52^{\circ} \mathrm{C}$ and $\lambda=3$

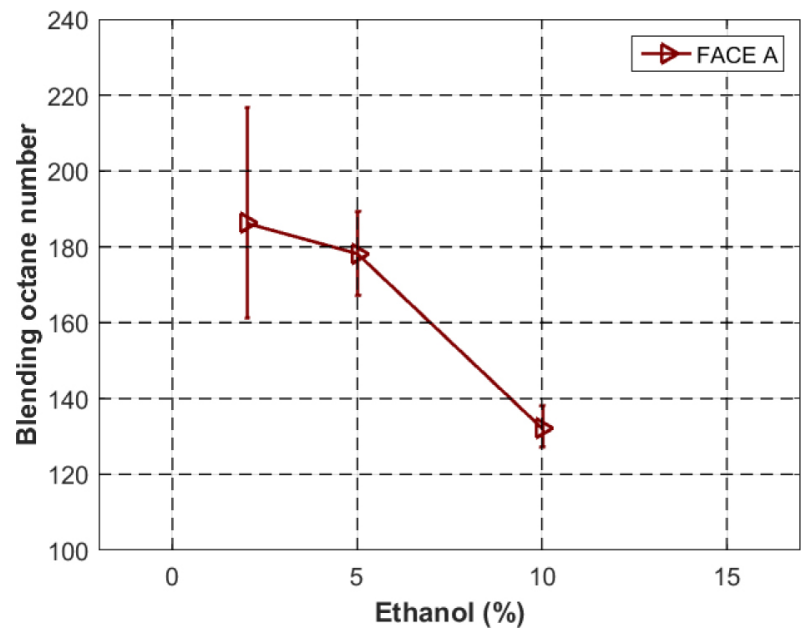

Figure A18. Uncertainty in Blending octane number for FACE A at $600 \mathrm{rpm}, \mathrm{T}_{\text {in }}=52^{\circ} \mathrm{C}$ and $\lambda=3$ 


\section{Appendix E (Incremental Blending Octane number (IBON)}

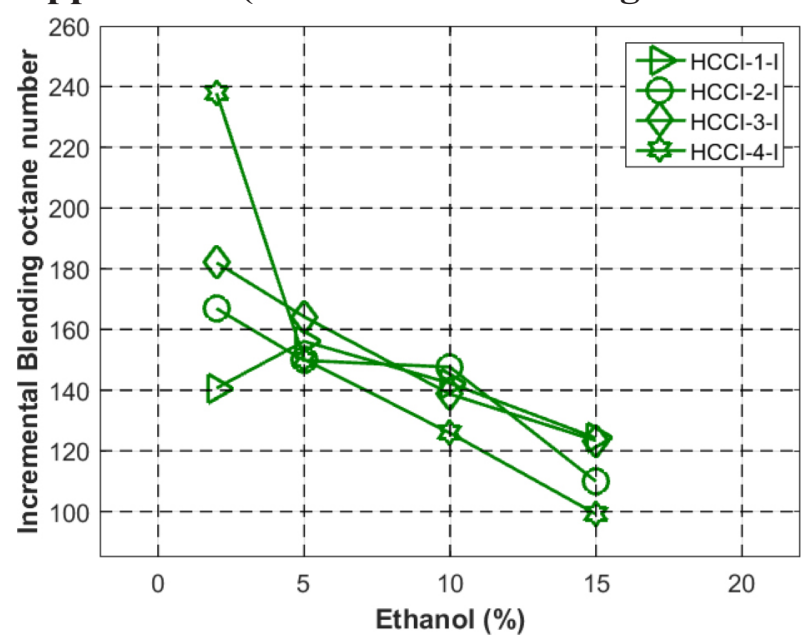

Figure A19. Incremental Blending octane number for FACE I, $\lambda=3$

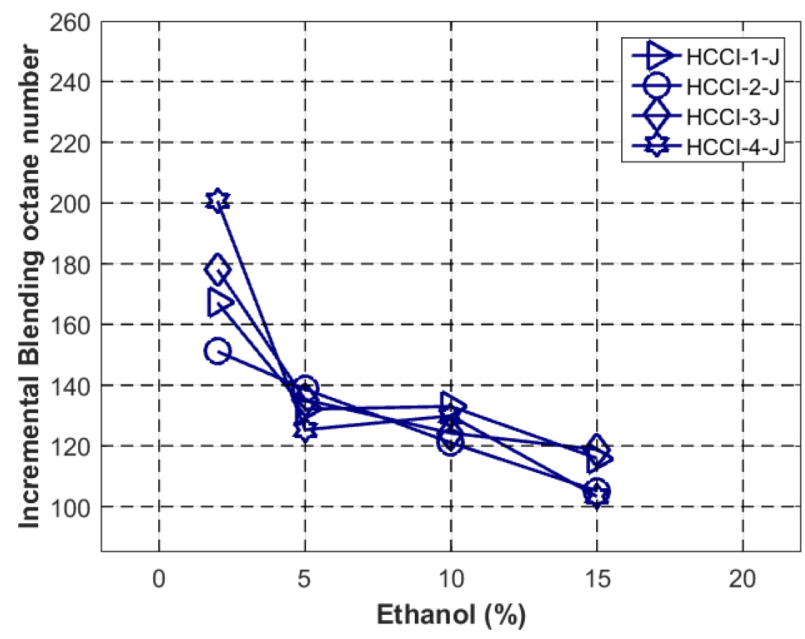

Figure A20. Incremental Blending octane number for FACE J, $\lambda=3$

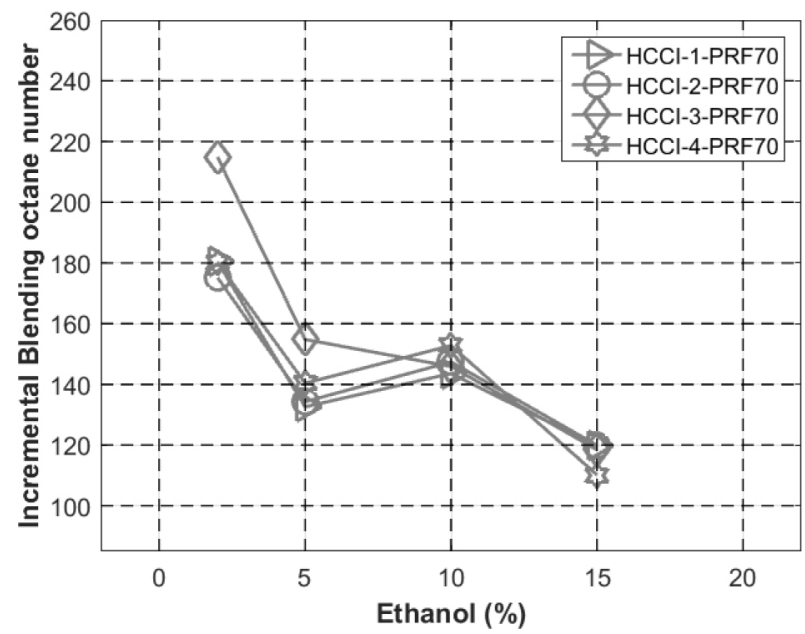

Figure A21. Incremental Blending octane number for PRF70, $\lambda=3$ 


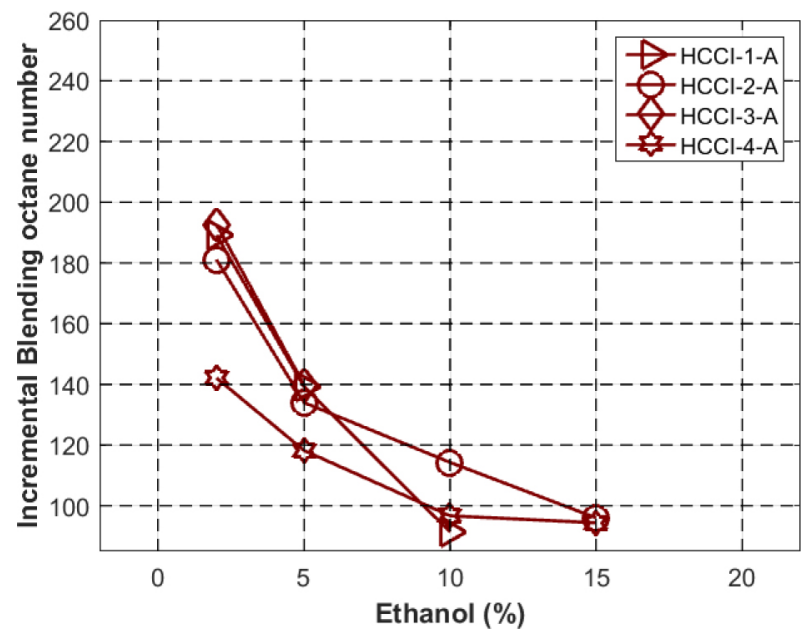

Figure A22. Incremental Blending octane number for FACE A, $\lambda=3$

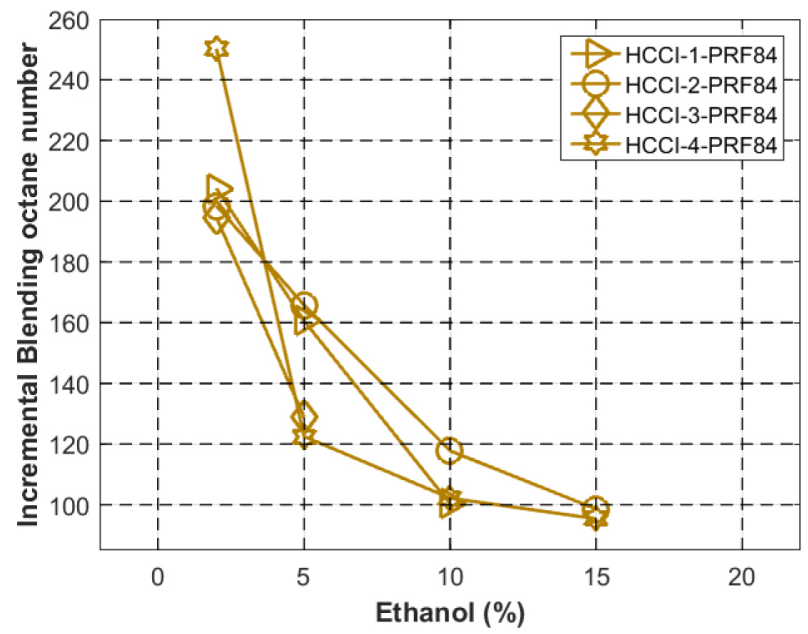

Figure A23. Incremental Blending octane number for PRF84, $\lambda=3$

All rights reserved. No part of this publication may be reproduced, stored in a retrieval system, or transmitted, in any form or by any means, electronic, mechanical, photocopying, recording, or otherwise, without the prior written permission of SAE International.

Positions and opinions advanced in this paper are those of the author(s) and not necessarily those of SAE International. The author is solely responsible for the content of the paper. 